\title{
Ideologia, sofisticação política e voto no Brasil
}

\author{
Mauricio Yoshida Izumi ${ }^{1}$ (i)
}

\begin{abstract}
A teoria espacial do voto parte do pressuposto de que eleitores diante de dois ou mais candidatos escolherão aquele que estiver mais próximo de suas preferências. O primeiro objetivo deste artigo é testar esse pressuposto para as eleições presidenciais no Brasil entre 2002 e 2014. Para isso utilizamos os dados do Estudo Eleitoral Brasileiro e as técnicas de escalonamento. Os resultados apontam que a probabilidade de um eleitor votar no candidato que está mais próximo dele do ponto de vista ideológico é extremamente alta. O segundo objetivo do artigo é verificar se esse resultado se sustenta a despeito do nível de sofisticação política do eleitor. Isto é, testamos a hipótese de que eleitores pouco informados tomariam as suas decisões a partir de elementos não espaciais (não ideológicos). Os resultados contrariam essa ideia. Eleitores pouco sofisticados do ponto de vista político também escolhem os candidatos que estão mais próximos deles.
\end{abstract}

Palavras-chave: eleições; ideologia; sofisticação política; teoria espacial do voto

\section{Introdução}

Quão próximas das preferências dos eleitores estão as preferências dos governantes? Essa questão é fundamental para a ciência política contemporânea, pois, como lembra Dahl (1997, p. 25), "uma característica-chave da democracia é a contínua responsividade do governo às preferências de seus cidadãos".

A teoria espacial do voto (Downs, 1957; Enelow e Hinich, 1984) tem dado muitas contribuições para iluminar essa questão. O seu principal pressuposto é que indivíduos diante de duas ou mais escolhas preferirão aquela que estiver mais próxima de suas visões. O primeiro objetivo deste artigo é testar esse pressuposto para o Brasil. Mais especificamente, vamos testar o modelo espacial nas eleições presidenciais de 2002 a 2014.

Parece trivial afirmar que eleitores de esquerda tendem a votar no candidato de esquerda e eleitores de direita, no candidato de direita. No entanto, parte importante da literatura que tratou da relação entre ideologia e voto no Brasil afirma que apenas uma parcela muito reduzida da população se comportaria dessa forma (Carreirão, 2002, p. 17).

\footnotetext{
1 Fundação Getúlio Vargas - Centro de Política e Economia do Setor Público. São Paulo (SP), Brasil. E-mail: <mauricioizumi@hotmail.com>.

2 O autor contou com apoio da Fapesp, processo número 2018/08118-4.
} 
O raciocínio parte do fato de que a maioria do eleitorado brasileiro é composta por indivíduos pobres e pouco escolarizados. Tais eleitores seriam também pouco informados do ponto de vista político (Castro, 1994; Reis e Castro, 2006; Pereira, 2013). Na visão de Ames e Smith (2010, p. 29), por serem pouco informados, esses eleitores não escolheriam os políticos que melhor representariam as suas reais preferências. Assim, a representação política seria trocada por interesses locais ou pela distribuição de políticas clientelistas.

Dito em outras palavras, a decisão do voto de uma parcela significativa do eleitorado brasileiro seria baseada exclusivamente em componentes não espaciais. Justamente por serem pouco escolarizados e pouco sofisticados do ponto de vista político, os eleitores não teriam os requisitos básicos para um voto ideológico. O segundo objetivo deste artigo é testar essas afirmações. Vamos verificar se eleitores pouco informados tendem a se comportar de uma forma não prevista pelo modelo espacial.

Na seção "Ideologia, voto e questões metodológicas", apresentamos a principal estratégia adotada pela literatura brasileira para medir a ideologia dos eleitores e o problema decorrente dela. Os estudos que se propuseram a avaliar o impacto da ideologia sobre o voto basearam as suas medidas nos dados brutos da autolocalização na escala esquerda-direita. O problema dessas medidas é a incomparabilidade interpessoal (Brady, 1985; King et al., 2004). Na seção "Escalonamento bayesiano de Aldrich-McKelvey", apresentamos a solução para esse problema. Utilizamos a solução proposta por Aldrich e McKelvey (1977) e implementada em uma versão bayesiana por Hare et al. (2014). Em seguida, na seção "Modelo estatístico", apresentamos o modelo estatístico de Jessee (2012), que utilizamos para testar o modelo espacial. Partindo de poucos pressupostos, esse modelo conecta os parâmetros do modelo básico da teoria espacial do voto aos coeficientes de um modelo de regressão probit. Na seção "Dados e estatística descritiva", temos os dados utilizados neste artigo, os do Estudo Eleitoral Brasileiro (Eseb) de 2002, 2006, 2010 e 2014 (Cesop, 2002, 2006, 2010, 2014). Na seção "Resultados", mostramos que a probabilidade de um eleitor votar no candidato que está mais próximo dele do ponto de vista ideológico é extremamente alta. Isto é, eleitores brasileiros se comportam como o modelo espacial pressupõe. Na seção "Sofisticação política e voto", vemos que isso independe do nível de sofisticação política dos eleitores. Eleitores pouco informados também tomam as suas decisões a partir da distância relativa dos candidatos. Na última seção, concluímos.

\section{Ideologia, voto e questões metodológicas}

Nesta seção revisamos alguns trabalhos que tratam da relação entre identificação ideológica e voto no Brasil, bem como apontamos as suas limitações. Como o objetivo deste artigo é testar o principal pressuposto da teoria espacial do voto, nos concentramos nos trabalhos que seguem uma abordagem semelhante. No entanto, antes disso, é importante notar que o conceito de voto ideológico não é consensual na ciência política. Para uma parte da literatura, a ideologia está diretamente relacionada ao conceito de 
sistema de crenças estruturado. De acordo com Converse (1964, p. 207), um sistema de crenças é "uma configuração de ideias e atitudes cujos elementos são interligados por alguma forma de constrangimento ou interdependência funcional". Assim, um indivíduo ideológico seria aquele que possui um conjunto de opiniões políticas que são interconectadas e estáveis ao longo do tempo. Esse eleitor estruturaria as suas opiniões políticas em consonância com a ideologia de que se diz adepto. Apenas uma pequena parcela da população estaria sob essa rubrica (Campbell et al., 1980). A maioria da população votaria com base na identificação partidária que seria formada no processo de socialização. Esse processo seria um reflexo direto do ambiente social imediato, principalmente o ambiente familiar.

No contexto brasileiro, diversos trabalhos produzidos durante o regime militar apresentaram uma baixa associação entre as avaliações de questões políticas e a preferência partidária e a intenção de voto $^{3}$, fato que sugeriria a baixa estruturação ideológica do eleitorado. Lamounier (1978), em estudo sobre o município paulista de Presidente Prudente, concluiu que as correlações entre as avaliações do desempenho governamental em diversas áreas e a preferência partidária eram irrelevantes para todos os níveis educacionais. Reis (1978), por sua vez, estudando o caso de Juiz de Fora (MG), encontrou uma correlação razoável entre preferência partidária e importantes questões político-institucionais da época. Mas, ao analisar questões de cunho local, o autor encontrou associações mais fracas.

Para o período recente, diversos autores argumentam que os eleitores não estruturam as suas preferências políticas em consonância com as ideologias de que se dizem adeptos (Almeida, 2001; Oliveira e Turgeon, 2015). De acordo com Oliveira e Turgeon (2015), nem mesmo para o pequeno grupo de eleitores politicamente sofisticados a ideologia constringe as preferências em temas relacionados ao papel do Estado na economia.

Na visão de Reis (2000), a grande massa do eleitorado brasileiro seria incapaz de relacionar importantes temas do debate político com opiniões esperadas por alguém de sua classe. Da mesma forma, a natureza da identificação partidária não teria nenhuma relação com o conteúdo de suas ações, ou seja, não teria nada de ideológico. Antes sim, seria uma identificação difusa e de conteúdo rarefeito. Os eleitores criariam uma imagem tosca dos partidos, estabelecida a partir de relações afetivas sem ligação com os conteúdos das políticas.

Castro (1994) possui uma visão semelhante e aponta para o papel fundamental da sofisticação política para o entendimento do comportamento eleitoral no Brasil. De acordo com a autora, apenas os eleitores mais sofisticados politicamente são capazes de orientar os seus votos a partir das opiniões sobre as diversas dimensões da política. Além disso, somente nesse estrato é que essas opiniões possuem uma clara relação com as posições na escala ideológica que os eleitores afirmam ter. Por sua vez, os eleitores pouco

\footnotetext{
3 Para uma crítica a esses trabalhos, ver Soares (2000).
} 
sofisticados, que compõem a maior parte do eleitorado, são desinformados sobre o debate político e as propostas oferecidas pelos candidatos. É comum que esses eleitores também tenham uma visão equivocada sobre as posições políticas dos partidos e dos candidatos.

Outra parte da literatura tem uma visão menos exigente e não requer que os eleitores estruturem as suas opiniões ou que sejam politicamente informados. Para essa corrente, a ideologia ou identificação ideológica é entendida como uma adesão a um posicionamento na escala esquerda-direita que sinaliza a imagem que o indivíduo possui daquilo que seria uma sociedade ideal e quais seriam os meios para construí-la (Downs, 1957; Hinich e Munger, 1994). Assim, não é necessário que os eleitores possuam uma alta sofisticação, nem que tenham um pensamento estruturado de forma lógica. Justamente por não conseguirem relacionar cada decisão tomada pelos governos com as próprias posições políticas é que a ideologia seria útil. Ela serve como um atalho informacional que reduz os custos da decisão eleitoral. Portanto, sob essa abordagem, o voto ideológico se realizaria mediante a simples comparação do posicionamento ideológico do eleitor com as posições ideológicas dos candidatos. O eleitor ideológico é aquele que escolhe o candidato que possui a posição mais próxima da sua sem levar em consideração outros elementos. Seguindo uma abordagem semelhante, diversos trabalhos buscaram testar empiricamente essas ideias para o caso brasileiro.

Singer (1999) foi quem introduziu no Brasil a ideia de que a ideologia é um fator central na escolha eleitoral. De acordo com ele, a identificação ideológica - entendida como a adesão difusa a uma posição na escala esquerda-direita que sinaliza uma orientação geral do eleitor na arena política - é um componente fundamental na explicação do voto nas eleições presidenciais. O autor analisou as eleições de 1989 e 1994 e utilizou a autolocalização na escala esquerda-direita para medir a identificação ideológica dos eleitores. Os seus resultados apontam para uma forte associação dessa variável com a escolha eleitoral.

Analisando as três eleições presidenciais ocorridas entre 1989 e 1998, Carreirão (2002) chegou a uma conclusão diferente. Apenas a parcela mais escolarizada do eleitorado utiliza a dimensão ideológica como guia na escolha política. Segundo ele (Carreirão, 2002, p. 17), o Brasil não tem um eleitorado "altamente informado e que vota ideologicamente no partido cujas posições políticas mais se aproximem das suas; apenas uma minoria, concentrada especialmente entre os eleitores de maior escolaridade, comporta-se desta forma". A maioria dos eleitores decide o seu voto com base em certas imagens políticas que eles formam dos partidos e dos candidatos. Além disso, a avaliação do desempenho do governo e a avaliação de atributos pessoais dos candidatos seriam outros fatores relevantes.

Holzhacker e Balbachevsky (2007), por sua vez, analisaram os impactos da estratificação social e da identidade ideológica sobre o voto nas eleições presidenciais de 2002 e 2006. De acordo com as autoras, nas eleições de 2002, a estratificação social foi pouco relevante para prever o voto para presidente. Por outro lado, a autolocalização na escala ideológica influenciou significativamente a decisão eleitoral. Eleitores de esquerda 
tinham mais chances de votar no candidato de esquerda e eleitores de direita, de votar no candidato de direita. Porém, os resultados para a eleição de 2006 apontaram para um cenário diferente. Nesse pleito, a estratificação social se mostrou uma variável importante na predição do voto, ao mesmo tempo em que a questão ideológica perdeu a sua força explicativa.

Resultado semelhante foi encontrado por Carreirão (2007) para as eleições de 2006. As suas análises apontam para a redução do poder explicativo da variável ideologia como preditora do voto, quando comparado aos pleitos anteriores. A correlação entre identificação ideológica e voto foi fraca. Apenas para o estrato de eleitores com nível superior houve uma correlação de magnitude moderada. A explicação para isso seria que, após os escândalos de corrupção e da política econômica adotada no primeiro mandato do presidente Lula, houve uma diminuição das diferenças ideológicas entre os partidos na visão dos eleitores. Como consequência dessa diluição, houve uma redução da associação entre identificação ideológica e voto.

Analisando as eleições de 2010, Nicolau (2014) explorou o impacto de diversas variáveis sobre o voto dos principais candidatos a presidente (Dilma, Serra e Marina), dentre elas o autoposicionamento na escala esquerda-direita. $O$ autor transformou a escala ideológica de 11 pontos em três categorias: esquerda (de 0 a 3), centro (de 4 a 6 ) e direita (de 7 a 10). Os resultados apontam que a probabilidade do voto na candidata do PT é alta em todo o espectro ideológico. Isto é, mesmo eleitores que se posicionaram como de centro, de direita ou não se posicionaram tinham uma alta probabilidade de votar em Dilma. Já a probabilidade de se votar no candidato do PSDB aumentava da esquerda para a direita.

Para as eleições de 2014, Amaral e Ribeiro (2015) exploraram um conjunto de 15 variáveis para determinar quais fatores foram relevantes na escolha eleitoral nos dois turnos das eleições presidenciais. Essas variáveis cobrem um amplo conjunto de dimensões de avaliação retrospectiva e prospectiva, questões contextuais, socioeconômicas e demográficas e de identidade política. Nessa última dimensão, está incluído o posicionamento ideológico, que apresentou resultados contraditórios. No primeiro turno, ter qualquer posicionamento aumentou as chances de se votar no candidato Aécio Neves. No entanto, no segundo turno, aqueles que se posicionaram à direita do espectro estavam mais propensos a votar no PSDB e aqueles que se posicionaram à esquerda estavam mais propensos a votar na petista.

Em resumo, não há consenso na literatura sobre qual a importância da variável ideologia como determinante do voto no período recente. Alguns trabalhos encontraram resultados favoráveis para a hipótese de que eleitores votam nos candidatos que estão mais próximos deles na dimensão ideológica, como sustenta a teoria espacial do voto. Outros trabalhos, porém, concluíram que outras variáveis, como a classe social e avaliações do desempenho do governo, são mais relevantes.

A despeito dessas diferenças, esses trabalhos têm uma característica em comum: todos utilizaram os dados brutos do autoposicionamento como medida da posição dos 
eleitores na escala ideológica - ou agregaram esses dados em categorias (esquerda, centro e direita) $)^{4}$.

O problema de utilizar os dados brutos é que os entrevistados podem interpretar a escala ideológica de formas muito diferentes. Dois indivíduos com as mesmas posições políticas podem se localizar na escala ideológica em lugares distintos. Assim como indivíduos com visões de mundo completamente diferentes podem se localizar no mesmo lugar da escala ideológica. De maneira semelhante, um eleitor de direita pode ver um candidato de centro-esquerda como um extremista de esquerda e um eleitor de esquerda pode ver o mesmo candidato como sendo de direita. Esse é o problema da incomparabilidade interpessoal dessas escalas (Brady, 1985; King et al., 2004). Por exemplo, quando um eleitor se localiza na posição de número 5 em uma escala ideológica de 10 pontos, não sabemos se ele se considera de centro, de esquerda ou de direita. A resposta depende de como ele utiliza essa escala.

\section{Escalonamento bayesiano de Aldrich-McKelvey}

Para contornar o problema da incomparabilidade interpessoal, utilizamos a solução proposta por Aldrich e McKelvey (1977) e implementada em uma versão bayesiana por Hare et al. (2014). Essa solução desenvolvida no final dos anos de 1970 ainda é largamente utilizada pela literatura internacional (Hare et al., 2014; Lo, Proksch e Gschwend, 2014; Saiegh, 2015). No entanto, no Brasil são raros os esforços nessa direção ${ }^{5}$. A solução está baseada no pressuposto de que, em geral, os eleitores sabem a ordem correta dos estímulos (partidos e candidatos), embora eles não saibam exatamente onde eles estão. Por exemplo, dificilmente ouvimos alguém dizer que o candidato José Serra (PSDB) é mais de esquerda do que a candidata Dilma Rousseff (PT). Mesmo que o eleitor não saiba exatamente qual é a localização deles na escala ideológica, ele provavelmente irá posicioná-los na ordem correta. Se isso for verdade, as respostas dos eleitores aos estímulos podem ser entendidas como uma transformação linear das posições "reais" dos candidatos mais um termo de erro aleatório. Assim, se estimarmos os parâmetros de distorção dos entrevistados, podemos recuperar as posições "reais" dos estímulos e dos próprios entrevistados.

Em termos mais formais, seja: $\zeta_{\mathrm{j}}$ a posição "real" do estímulo $j=\{1, \ldots, m\} ; z_{\mathrm{ij}}$ a posição do estímulo $j$ reportada pelo entrevistado $i=\{1, \ldots, n\} ; a_{i}$ e $\beta_{i}$ escalares; e $\varepsilon_{i j}$ um termo de erro aleatório. As respostas dos entrevistados aos estímulos podem ser escritas como:

$$
z_{i j}=a_{i}+\beta_{i} \zeta_{j}+\varepsilon_{i j}
$$

\footnotetext{
4 Carreirão (2007), por exemplo, agrupa as posições na escala de 0 a 10 da seguinte forma: esquerda, de 0 a 3; centro, de 4 a 6; e direita, de 7 a 10. Já Singer (1999), utilizando uma escala de 1 (esquerda) a 7 (direita), agrupou os dados como seguem: esquerda, de 1 a 2; centro, de 3 a 5; e direita, de 6 a 7.

5 A exceção é o trabalho de Power e Zucco Jr. (2009) que utilizou esse modelo para estimar as posições ideológicas dos partidos políticos a partir de entrevistas com parlamentares.
} 
Estimar os parâmetros $a_{i}$ e $\beta_{i}$ nada mais é do que regredir as posições dos candidatos reportadas pelos entrevistados sobre as posições "reais" não observadas dos candidatos.

Com esses parâmetros podemos recuperar as posições "reais" dos candidatos. E se assumirmos que os entrevistados utilizam a mesma escala para posicionar os candidatos e se autoposicionarem, temos que a "real" posição (ponto ideal) de um eleitor $i$ é dada por:

$$
\mathrm{X}_{\mathrm{i}}=\frac{\mathrm{zii}-\alpha \mathrm{i}}{\beta i}
$$

onde $z_{i i}$ é a autolocalização do entrevistado $i$.

Em sua implementação bayesiana (Hare et al., 2014) assume-se que:

$$
\begin{aligned}
z_{i j} & \sim N\left(\mu_{i j}, T_{i j}\right) \\
\mu_{i j} & =a_{i}+\beta_{i} \zeta_{j} \\
T_{i j} & =T_{i} T_{j}
\end{aligned}
$$

Para completarmos o modelo, atribuímos uma distribuição a priori para os parâmetros de interesse:

$$
\begin{aligned}
\mathrm{a}_{\mathrm{i}} & \sim \mathrm{U}(-100,100) \\
\beta_{\mathrm{i}} & \sim \mathrm{U}(-100,100) \\
\zeta_{\mathrm{j}} & \sim \mathrm{N}(0,1) \\
\mathrm{T}_{\mathrm{i}} & \sim \operatorname{Gamma}(0,1 ; 0,1) \\
\mathrm{T}_{\mathrm{j}} & \sim \operatorname{Gamma}(\mathrm{V}, \mathrm{W}) \\
\mathrm{v} & \sim \operatorname{Gamma}(0,1 ; 0,1) \\
\mathrm{W} & \sim \operatorname{Gamma}(0,1 ; 0,1)
\end{aligned}
$$

Para definirmos a polaridade da escala e identificarmos o modelo, precisamos fixar dois estímulos (Clinton, Jackman e Rivers, 2004). Fixamos o candidato do PT em -0,25 e o candidato do PSDB em 0,25. A escolha desses valores é importante para deduzirmos o modelo estatístico da próxima seção. Todos os modelos deste artigo foram estimados pelo método de Monte Carlo via cadeias de Markov e foram implementados em JAGS utilizando o pacote rjags do $R$. Geramos 110.000 amostras, descartamos as 100.000 primeiras e retivemos as restantes por um fator de 10 . Isso produziu um conjunto de 1.000 amostras.

\section{Modelo estatístico}

Para testarmos os pressupostos da teoria espacial do voto no Brasil, utilizamos o modelo proposto por Jessee (2012, p. 78-81). Partindo de um modelo probabilístico da teoria espacial do voto, escrevemos a função de utilidade de um eleitor $i$ votar em um candidato $k$ como: 


$$
\mathrm{U}_{\mathrm{i}}(\mathrm{k})=-\mathrm{a}\left(\mathrm{x}_{\mathrm{i}}-\mathrm{c}_{\mathrm{k}}\right)^{2}+\mathrm{b}_{\mathrm{k}}+\mathrm{e}_{\mathrm{ik}}
$$

onde $x_{i}$ é o ponto ideal do eleitor $i$ e $c_{k}$ é a posição do candidato $k$. Considerando que analisamos o segundo turno das eleições presidenciais entre 2002 e 2014, temos que $c_{k}$ assume apenas dois valores, CPSDB e CPT. Já $b_{k}$ é um termo que indica a tendência ou disposição de o eleitor votar no candidato $k$, a despeito de sua proximidade. Ele indica uma vantagem baseada em elementos não espaciais, como o carisma, o gênero ou o desempenho anterior do candidato (Enelow e Hinich, 1982). Aqui ele assume dois valores $b_{\text {PSDB }}$ e $b_{\text {PT. }} e_{i k}$ é o termo de erro aleatório independente dos eleitores e dos candidatos com $\mathrm{e}_{\mathrm{ik}} \sim \mathrm{N}(0 ; 0,5)$. A escolha dessa distribuição é importante para a dedução do modelo estatístico. O parâmetro $a$ indica o quanto a utilidade do eleitor em votar em um candidato está relacionada com a sua proximidade (policy weight).

A partir dessa função de utilidade, podemos calcular a probabilidade de um eleitor $i$ votar no candidato do PSDB como:

$$
\begin{aligned}
P\left(v_{i}=\right. & P S D B)=P\left(U_{i}(P S D B)>U_{i}(P T)\right) \\
& =P\left(-a\left(x_{i}-C_{P S D B}\right)^{2}+b_{P S D B}+e_{i P S D B}>-a\left(x_{i}-c_{P T}\right)^{2}+b_{P T}+e_{i P T}\right) \\
& =P\left(-a\left(x_{i}-c_{P S D B}\right)^{2}+b_{P S D B}+a\left(x_{i}-c_{P T}\right)^{2}-b_{P T}>e_{i P T}-e_{i P S D B}\right) \\
& =P\left(-a\left(x_{i}^{2}-2 x_{i} C_{P S D B}+c^{2}{ }_{P S D B}\right)+a\left(x_{i}^{2}-2 x_{i} C_{P T}+c^{2}{ }_{P T}\right)+b_{P S D B}-b_{P T}\right. \\
& \left.>e_{i P T}-e_{i P S D B}\right) \\
& =P\left(2 a x_{i}\left(C_{P S D B}-C_{P T}\right)+a\left(c^{2}{ }_{P T}-c^{2}{ }_{P S D B}\right)+b_{P S D B}-b_{P T}>e_{i P T}-e_{i P S D B}\right) \\
& =\Phi\left(\lambda x_{i}+n+\delta\right)
\end{aligned}
$$

onde $\lambda=2 a\left(C_{P S D B}-C_{P T}\right) ; n=a\left(c^{2} P T-c^{2}{ }_{P S D B}\right) ; \delta=b_{P S D B}-b_{P T} ;$ e $\Phi($.$) é a função de distribuição$ acumulada da normal-padrão. A passagem da penúltima para a última linha da equação 14 é possível porque assumimos que $\mathrm{e}_{\mathrm{iPT}}$ e $\mathrm{e}_{\mathrm{PPSDB}}$ seguem a distribuição normal com média 0 e variância 0,5 . Com isso, $\left(\mathrm{e}_{\mathrm{iPT}}-\mathrm{e}_{\mathrm{iPSDB}}\right) \sim \mathrm{N}(0,1)$.

Como é possível notar, podemos escrever essa probabilidade como um modelo de regressão probit:

$$
P\left(v_{i}=P S D B\right)=\Phi\left(Y_{0}+Y_{1} x_{i}\right)
$$

onde a correspondência entre os coeficientes da regressão, $Y_{0}$ e $\gamma_{1}$, e o modelo espacial da equação 13 é expressa por:

$$
\begin{gathered}
Y_{1}=\lambda=2 a\left(C_{P S D B}-C_{P T}\right) \\
Y_{0}=\pi+\delta=\begin{array}{l}
a\left(c^{2}{ }_{P T}-c^{2} P S D B\right. \\
\end{array}+\left(b_{P S D B}-b_{P T}\right)
\end{gathered}
$$

Como fixamos na seção anterior $\mathrm{CPSDB}_{\mathrm{PSB}}=0,25$ e $\mathrm{C}_{\mathrm{PT}}=-0,25$, podemos resolver as equações de (16) em termos de $a, \delta$ e $\Pi$, e concluir que:

$$
\begin{gathered}
a=\frac{\gamma 1}{2(\mathrm{cPSDB}-\mathrm{cPT})}=\frac{\gamma 1}{2(0,25-(-0,25))}=\mathrm{Y}_{1} \\
\delta=\mathrm{Y}_{0}-\mathrm{a}\left(\mathrm{c}^{2} \mathrm{PT}-\mathrm{c}^{2} \mathrm{PSDB}\right)=\mathrm{Y}_{0}-\frac{\gamma 1(\mathrm{c} 2 \mathrm{PT}-\mathrm{c} 2 \mathrm{PSDB})}{2(\mathrm{cPSDB}-\mathrm{cPT})}=\mathrm{Y}_{0}-\frac{\gamma 1((0,25) 2-(-0,25) 2)}{2(0,25-(-0,25))}=\mathrm{Y}_{0}
\end{gathered}
$$




$$
\Pi=\mathrm{a}\left(\mathrm{C}^{2} \mathrm{PT}-\mathrm{C}^{2} \mathrm{PSDB}\right)=\frac{\gamma 1(\mathrm{c} 2 \mathrm{PT}-\mathrm{c} 2 \mathrm{PSDB})}{2(\mathrm{cPSDB}-\mathrm{cPT})}=\frac{\gamma 1((0,25) 2-(-0,25) 2)}{2(0,25-(-0,25))}=0
$$

Assim, o modelo proposto por Jessee (2012) conecta os parâmetros do modelo espacial diretamente aos coeficientes do modelo de regressão. Em termos substantivos, se $a$ for positivo, maior é a probabilidade de um eleitor de esquerda (ou direita) votar no candidato de esquerda (ou direita). Esperamos encontrar um valor positivo para esse parâmetro.

Como $\delta$ é a diferença entre o viés em relação ao candidato do PSDB e o viés em relação ao candidato do PT ( $\left.\delta=b_{P S D B}-b_{P T}\right)$, temos que: se $\delta>0$, temos um viés do eleitorado em relação ao candidato do PSDB; se $\delta<0$, temos um viés em relação ao candidato do PT; e se $\delta=0$, os eleitores não estão viesados em nenhuma direção.

\section{Dados e estatística descritiva}

Os dados que utilizamos neste artigo são do Estudo Eleitoral Brasileiro (Eseb de 2002, 2006, 2010 e 2014). O Eseb é coordenado pelo Centro de Estudos de Opinião Pública (Cesop) da Universidade Estadual de Campinas (Unicamp) e é largamente utilizado por cientistas políticos brasileiros, pois cobre uma grande variedade de temas. Em particular, utilizamos os tópicos relacionados ao autoposicionamento dos entrevistados e posicionamento dos partidos e dos candidatos em uma escala ideológica. Essa escala vai de 0 a 10, sendo que 0 significa ser de esquerda e 10, de direita. Nas questões relacionadas ao posicionamento dos partidos políticos, é perguntado aos entrevistados: "Na política as pessoas falam muito de esquerda e de direita. Gostaria que o(a) $\operatorname{sr}(a)$. usasse um número de 0 a 10 para dizer se o partido político que eu vou dizer é de esquerda ou de direita. Quando eu falar o nome de um partido que o(a) $\operatorname{sr}(a)$. não conhece, apenas diga que não o conhece. Como classificaria o _?". Nesse espaço em branco, o entrevistador diz o nome do partido (PT, PSDB, PMDB...). De maneira semelhante, para as questões sobre o posicionamento dos políticos, é oferecida uma lista com o nome dos políticos (Aécio Neves, Ciro Gomes, Dilma Rousseff, José Serra.... ${ }^{6}$. Na questão do autoposicionamento, é perguntado ao entrevistado: "Como o(a) sr(a). se considera? 0 significa que o(a) sr(a). é de esquerda e 10 que o (a) sr(a). é de direita". Para todas as questões o entrevistado deve escolher um número inteiro dentro do intervalo $[0,10]$.

\footnotetext{
${ }^{6}$ A pergunta é: "Agora eu gostaria que o(a) sr(a). usasse um número de 0 a 10 para dizer qual político é de esquerda e qual é de direita. 0 significa que o político é de esquerda e 10 que é de direita. De 0 a 10 como o(a) sr(a). classificaria o_?".
} 
Tabela 1

Dados utilizados

\begin{tabular}{|l|c|c|c|c|}
\hline & $\mathbf{2 0 0 2}$ & $\mathbf{2 0 0 6}$ & $\mathbf{2 0 1 0}$ & $\mathbf{2 0 1 4}$ \\
\hline Entrevistados & 1.302 & 1.000 & 2.000 & 3.136 \\
\hline Entrevistados utilizados & $973(74,7 \%)$ & $536(53,6 \%)$ & $1077(53,9 \%)$ & $1501(47,9 \%)$ \\
\hline Questões de sofisticação & 22 & 9 & 31 & 23 \\
\hline Estímulos utilizados & $\begin{array}{c}\text { PT, PSDB, } \\
\text { PMDB, Lula, } \\
\text { Serra e } \\
\text { Garotinho }\end{array}$ & $\begin{array}{c}\text { PT, PSDB, } \\
\text { PMDB, Lula, } \\
\text { Alckmin e } \\
\text { Heloísa }\end{array}$ & $\begin{array}{c}\text { PM, PSDB, } \\
\text { Serra e Marina }\end{array}$ & PM, PSDB e \\
\hline CPSDB & Serra & Alckmin & Serra & PSDB \\
\hline CPT & Lula & Lula & Dilma & PT \\
\hline
\end{tabular}

Fonte: Elaborada pelo autor com base em dados dos Esebs.

Na Tabela 1, temos uma descrição dos dados utilizados ${ }^{7}$. Utilizamos como estímulos os três principais partidos (PT, PSDB e PMDB) e os três principais candidatos das eleições presidenciais. A exceção ficou por conta do Eseb do ano de 2014 que não possui questões sobre o posicionamento na escala ideológica dos candidatos, apenas dos partidos. Para medir a sofisticação política dos eleitores, utilizamos 4 questões sobre conhecimento político nos anos de 2002, 2006 e 2014 e 21 questões no ano de 2010 . As demais questões incluídas estão associadas à participação e ao interesse por política. Analisamos apenas os entrevistados que responderam à questão do autoposicionamento e que localizaram pelo menos um dos estímulos selecionados. Como vemos, o número de indivíduos que atendem a esses critérios cai ao longo do tempo. No entanto, a despeito do número de indivíduos, estímulos e questões sobre conhecimento político, os nossos resultados são semelhantes para todos os anos.

\footnotetext{
7 Cabe uma nota sobre o Eseb de 2002. O número total de entrevistados foi de 2.514 indivíduos. No entanto, cerca de metade da amostra (1.302) utilizou uma escala ideológica de 11 pontos na qual 0 significava ser de esquerda e 10 significava ser de direita. Mas a outra metade da amostra (1.212) utilizou uma escala invertida (0 significava direita e 10 significava esquerda). Limitamos a análise ao primeiro conjunto de entrevistados. Não há problemas em utilizar apenas essa amostra porque ambas são representativas da população-alvo.
} 


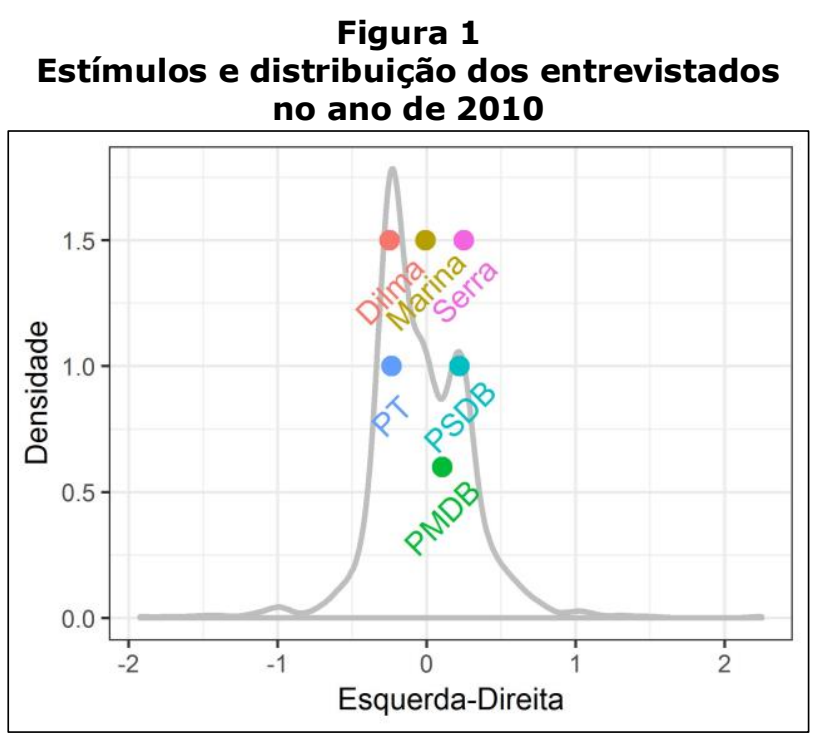

Fonte: Elaborada pelo autor com base em dados do Eseb de 2010.

Na Figura 1, apresentamos os pontos ideais dos entrevistados juntamente com as posições dos partidos e dos candidatos estimados pelo escalonamento bayesiano de Aldrich-McKelvey para o ano de $2010^{8}$. A distribuição em cinza representa os pontos ideais dos entrevistados e os pontos são os candidatos e os partidos. Em primeiro lugar, podemos notar a validade de nossos resultados. Os três candidatos estão ordenados da esquerda para direita no espectro ideológico, como seria esperado. A candidata Dilma Rousseff está mais à esquerda, o candidato José Serra mais à direita e entre eles está Marina Silva. Da mesma forma, os partidos políticos estão localizados como convencionalmente eles são vistos. Indo da esquerda para a direita, temos PT, PMDB e PSDB. Nota-se também a proximidade da posição dos partidos políticos com os seus respectivos candidatos (Dilma e Serra).

Ao comparar os pontos ideais estimados dos entrevistados com os dados brutos da autolocalização, vemos diferenças significativas (Figura 2 para o ano de $2010^{9}$ ). No gráfico da esquerda da Figura 2, temos os dados da autolocalização na escala ideológica. Nele observamos a tendência dos entrevistados em se localizarem nas categorias proeminentes, isto é, nos valores extremos 0 e 10 e no valor central 5. Mais da metade dos eleitores se classificaram em um desses três valores. Além disso, os dados brutos indicam um eleitorado mais à direita do espectro. Somando os indivíduos que se classificaram com valores maiores do que cinco, temos quase $60 \%$ dos entrevistados.

\footnotetext{
8 Os pontos ideais e as posições dos estímulos são a mediana da distribuição a posteriori. Por questões de espaço, mostramos apenas os resultados da eleição de 2010. Os resultados para as eleições de 2002, 2006 e 2014 estão nos Anexos (Figura 6).

9 Para os demais anos, ver os Anexos (Figura 7).
} 
Por outro lado, os resultados estimados mostram um cenário diferente. No gráfico da direita da Figura 2, temos um eleitorado localizado mais ao centro da escala em torno do 0 com uma distribuição próxima da normal.

Figura 2

Comparação entre 0 autoposicionamento

e os pontos ideais estimados no ano de $\mathbf{2 0 1 0}$

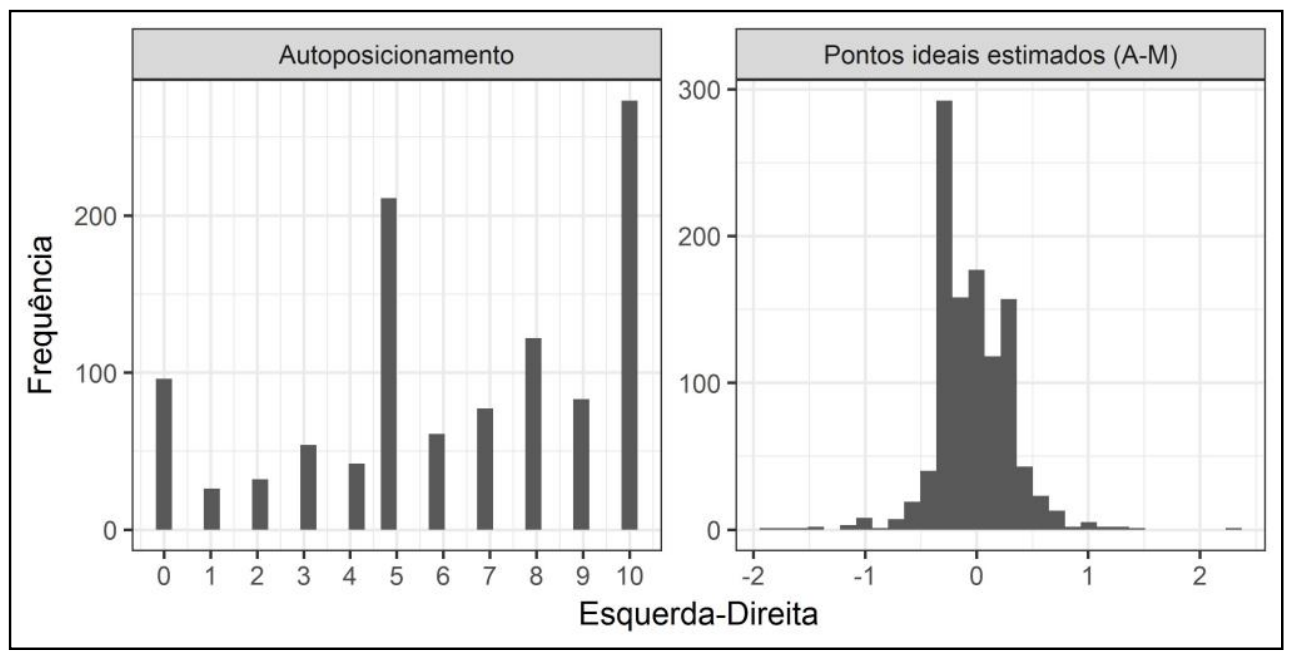

Fonte: Elaborada pelo autor com base em dados do Eseb de 2010.

É interessante notar que essas diferenças encontradas nas medidas da posição ideológica dos eleitores têm impactos substantivos na forma como vemos a relação entre ideologia e voto. Por exemplo, Carreirão (2007), ao analisar as eleições de 2002 e 2006, argumenta que a identificação ideológica parece ter perdido boa parte do poder analítico para o entendimento do voto nas eleições presidenciais. De acordo com ele,

\begin{abstract}
a tendência mais provável, no curto prazo, é a de que o próprio contínuo esquerda-direita perca parte do poder analítico (e preditivo) como referencial para a compreensão do comportamento dos partidos e dos eleitores, comparativamente ao poder que teve até recentemente (Carreirão, 2007, p. 332).
\end{abstract}

Podemos testar essa afirmação para as eleições de 2010. Para isso verificamos qual a relação entre voto e ideologia utilizando o coeficiente de correlação bisserial de ponto. As variáveis que vamos correlacionar indicam se o entrevistado votou no candidato José Serra no $2^{\circ}$ turno e o autoposicionamento na escala ideológica. O coeficiente de correlação aponta uma associação fraca entre as duas variáveis $(r=0,15)$. Esse resultado corrobora as previsões feitas por Carreirão (2007). Saber se um eleitor é de esquerda ou de direita parece não ser uma informação relevante, se quisermos prever o seu voto.

No entanto, se substituirmos a variável do autoposicionamento pelos pontos ideais estimados, encontramos uma associação mais forte $(r=0,38)$. Isto é, quando corrigimos 
as posições dos entrevistados utilizando o método proposto por Aldrich e McKelvey (1977), encontramos uma associação moderada entre ideologia e comportamento eleitoral. Esse resultado sugere que eleitores de direita tendem a escolher o candidato que está mais à direita da escala ideológica e eleitores de esquerda tendem a escolher o candidato que está mais à esquerda. Embora esses resultados sejam sugestivos, precisamos de um modelo que leve em consideração a distância da posição dos eleitores em relação aos candidatos para fazermos um teste mais acurado da teoria espacial do voto. Esse é o objetivo da próxima seção.

\section{Resultados}

Antes de apresentarmos a análise formal, na Figura 3 apresentamos a distribuição das preferências dos eleitores de acordo com o candidato escolhido no 20 turno das eleições de $2010^{10}$. Nela podemos ver que os eleitores que votaram na candidata Dilma Rousseff são aqueles que, em geral, estão mais à esquerda do espectro ideológico. Da mesma forma que os eleitores que votaram em José Serra estão mais à direita. Esses resultados são indícios favoráveis para a ideia de que eleitores votam nos candidatos que estão mais próximos deles do ponto de vista ideológico, como aponta a teoria espacial do voto.

Figura 3

\section{Distribuição dos entrevistados por voto nas eleições de $\mathbf{2 0 1 0}$}

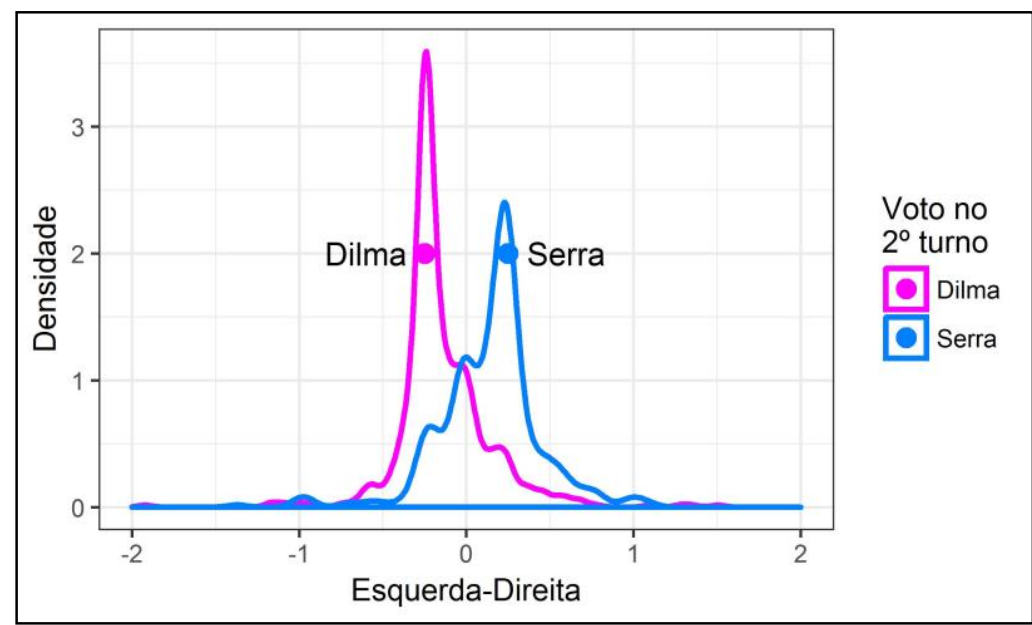

Fonte: Elaborada pelo autor com base em dados do Eseb de 2010.

Para estimar os parâmetros do modelo espacial proposto na equação 15 utilizamos um modelo bayesiano de regressão probit tendo como variável dependente um indicador de se o entrevistado votou no candidato do PSDB no segundo turno das eleições (PSDB =

10 Para os demais anos, ver os Anexos (Figura 8). 
$1 ; \mathrm{PT}=0$ ). A nossa variável independente é a mediana da distribuição a posteriori das posições ideológicas dos entrevistados $\left(\mathrm{x}_{\mathrm{i}}\right)$. Os resultados estão na Tabela 2:

Tabela 2

Estimativas dos parâmetros do modelo espacial

\begin{tabular}{|l|c|c|c|c|}
\hline & $\mathbf{2 0 0 2}$ & $\mathbf{2 0 0 6}$ & $\mathbf{2 0 1 0}$ & $\mathbf{2 0 1 4}$ \\
\hline \multirow{3}{*}{ Intercepto $(\delta)$} & $-0,54$ & $-0,50$ & $-0,26$ & $-0,07$ \\
\cline { 2 - 5 } & {$[-0,64 ;-0,45]$} & {$[-0,63 ;-0,38]$} & {$[-0,34 ;-0,17]$} & {$[-0,14 ; 0,00]$} \\
\hline \multirow{2}{*}{ Ponto ideal $(a)$} & 1,30 & 0,96 & 1,67 & 1,06 \\
\cline { 2 - 5 } & {$[1,01 ; 1,61]$} & {$[0,60 ; 1,28]$} & {$[1,41 ; 1,94]$} & {$[1,85 ; 1,27]$} \\
\hline $\mathrm{N}$ & 937 & 536 & 1077 & 1501 \\
\hline
\end{tabular}

Fonte: Elaborada pelo autor com base em dados dos Esebs.

Nota: As estimativas são a mediana da distribuição a posteriori. Intervalos de credibilidade de $95 \%$ estão entre colchetes.

O parâmetro $\delta$, que indica a diferença de viés dos eleitores em relação aos candidatos, possui um valor negativo. Isso indica um viés para os candidatos do PT. A despeito da proximidade ideológica, em média, os eleitores estavam predispostos a votar nos candidatos do PT. Ou seja, existia um componente não espacial, embora pequeno, favorável aos petistas.

Analisando o valor estimado do parâmetro a vemos que ele é positivo e com uma magnitude forte. Esse resultado indica que, quanto mais à esquerda da escala ideológica um eleitor está, maiores são as chances de ele votar no candidato de esquerda. Isto é, mais sensível à posição do candidato o eleitor está. 
Figura 4

Probabilidade do voto no candidato do PSDB em função dos pontos ideais dos entrevistados

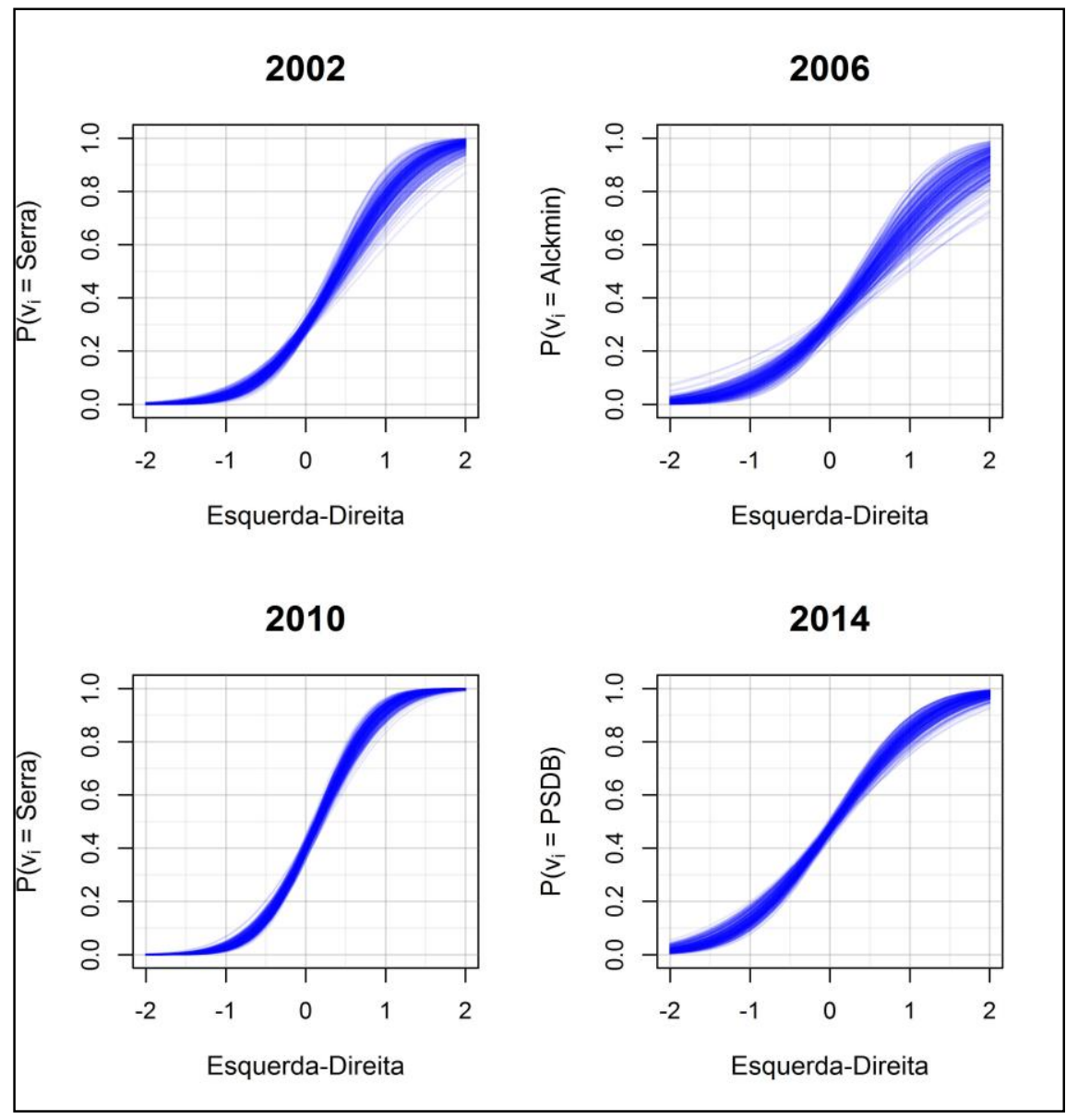

Fonte: Elaborada pelo autor com base em dados dos Esebs.

Nota: Cada gráfico possui 250 curvas calculadas a partir de 250 amostras da distribuição a posteriori dos coeficientes do modelo de regressão.

Podemos analisar também os gráficos com a probabilidade predita pelo modelo de se votar no candidato do PSDB em função dos pontos ideais dos entrevistados (Figura 4). Com isso temos uma noção mais clara da relação entre proximidade ideológica e escolha eleitoral. Por exemplo, para a eleição de 2010, um eleitor que possui um ponto ideal de 0,5 - e que, portanto, está a 0,25 ponto de distância da candidata Dilma e a 0,75 do candidato Serra - possui apenas $13,7 \%$ de chances de votar no candidato José Serra. Mas um eleitor que possui um ponto ideal de 0,5 - e que, portanto, está a 0,25 ponto de distância do candidato Serra e a 0,75 da candidata Dilma - possui 71,9\% de chances de escolher o candidato do PSDB. Para as eleições de 2002 e 2006, esses valores são um pouco mais baixos: $11,6 \%$ (2002) e 13,3\% (2006) para os eleitores com pontos ideais de $-0,5$ e $54,2 \%$ (2002) e 49,2\% (2006) para os eleitores com ponto ideal de 0,5. Já para a 
eleição de 2014, o fator ideológico foi mais forte. A chance de eleitores com ponto ideal de $-0,5$ votar no candidato do PSDB era de $27,5 \%$. Por outro lado, eleitores com ponto ideal de 0,5 a chance era de $67,9 \%$.

Outro ponto interessante de analisar é aquele que está exatamente entre os dois candidatos. Esse ponto médio que está localizado no $x_{i}=0$ é aquele em que o eleitor seria indiferente aos candidatos, caso não existisse viés. Ou seja, se nenhum candidato possuir uma vantagem baseada em elementos não espaciais, esperamos que a probabilidade de um eleitor votar em qualquer um dos dois candidatos seja igual a $50 \%$. Como observamos na Figura 4, para as eleições de 2010, um eleitor que possui um ponto ideal igual a zero tem $39,9 \%$ de chances de votar no candidato Serra. Esse resultado indica a existência de uma vantagem a favor da candidata Dilma Rousseff. Resultado semelhante foi encontrado para a eleição de 2014 (47,3\%) (Figura 4). Essa vantagem, por outro lado, é pequena em termos substantivos. Esse viés baseado em componentes não ideológicos foi mais forte durante os dois pleitos anteriores quando o candidato do PT foi o Lula. Eleitores no ponto de indiferença tinham 29,3\% (2002) e 30,8\% (2006) de chance de votar no candidato do PSDB (Figura 4).

Em resumo, a proximidade ideológica entre eleitores e candidatos está fortemente associada à escolha eleitoral. Eleitores de esquerda tendem a votar no candidato de esquerda e eleitores de direita tendem a votar no candidato de direita. No que diz respeito ao viés fruto de elementos não espaciais, os candidatos do PT possuem uma vantagem pequena em relação aos candidatos do PSDB. No entanto, essa vantagem tem diminuído ao longo do tempo. 
Tabela 3

Estimação dos parâmetros do modelo espacial com controles

\begin{tabular}{|c|c|c|c|c|}
\hline & 2002 & 2006 & 2010 & 2014 \\
\hline \multirow{2}{*}{ Intercepto } & $-1,02$ & 0,54 & 0,23 & 0,68 \\
\hline & {$[-1,26 ;-0,76]$} & {$[0,09 ; 0,94]$} & {$[-0,37 ; 0,80]$} & {$[0,59 ; 0,81]$} \\
\hline \multirow{2}{*}{ Ponto ideal } & 0,44 & 0,51 & 0,85 & 0,69 \\
\hline & {$[0,04 ; 0,82]$} & {$[0,07 ; 0,96]$} & {$[0,53 ; 1,23]$} & {$[0,43 ; 0,93]$} \\
\hline \multirow{2}{*}{ Avaliação do governo } & 0,53 & $-1,46$ & $-0,28$ & $-1,21$ \\
\hline & {$[0,27 ; 0,76]$} & {$[-1,88 ;-1,01]$} & {$[-0,83 ; 0,35]$} & {$[-1,39 ;-1,03]$} \\
\hline \multirow{2}{*}{ Gosta do PT } & $-0,59$ & $-1,00$ & $-0,98$ & $-1,50$ \\
\hline & {$[-0,87 ;-0,29]$} & {$[-1,67 ;-0,37]$} & {$[-1,25 ;-0,69]$} & {$[-1,87 ;-1,18]$} \\
\hline \multirow{2}{*}{ Gosta do PSDB } & 0,55 & 0,42 & 0,93 & 1,12 \\
\hline & {$[0,12 ; 0,99]$} & {$[-0,25 ; 1,02]$} & {$[0,58 ; 1,26]$} & {$[0,76 ; 1,47]$} \\
\hline \multirow{2}{*}{ Não votaria no PT } & 1,66 & 1,49 & 1,55 & - \\
\hline & {$[1,37 ; 1,95]$} & {$[1,09 ; 1,94]$} & {$[1,20 ; 1,96]$} & \\
\hline \multirow{2}{*}{ Não votaria no PSDB } & $-0,36$ & $-0,91$ & $-1,12$ & - \\
\hline & {$[-0,63 ;-0,08]$} & {$[-1,38 ;-0,48]$} & {$[-1,39 ;-0,82]$} & \\
\hline \multirow[t]{2}{*}{ Avaliação da economia } & - & - & $-0,06$ & $-0,09$ \\
\hline & & & {$[-0,29 ; 0,19]$} & {$[-0,29 ; 0,11]$} \\
\hline \multirow[t]{2}{*}{ Bolsa Família } & - & - & $-0,11$ & $-0,41$ \\
\hline & & & {$[-0,46 ; 0,23]$} & {$[-0,59 ;-0,22]$} \\
\hline $\mathrm{N}$ & 915 & 469 & 990 & 1450 \\
\hline
\end{tabular}

Fonte: Elaborada pelo autor com base em dados dos Esebs.

Nota: As estimativas são a mediana da distribuição a posteriori. Intervalos de credibilidade de $95 \%$ estão entre colchetes.

As estimativas geradas pelo modelo não têm uma interpretação causal. Os resultados expostos na Tabela 2 são estimativas de um modelo bivariado que leva em consideração apenas a posição ideológica dos eleitores como determinante do voto. Sabemos, no entanto, que essa não é a única variável relevante na decisão eleitoral. A avaliação da economia, a avaliação do governo, a identificação partidária e a rejeição a determinados candidatos, apenas para citar alguns exemplos, são outros fatores relevantes. Para contornar esse problema, incluímos diversas variáveis de controle ao modelo bivariado. Os resultados podem ser vistos na Tabela 3.

Em todos os anos incluímos uma variável que indica se o eleitor avaliou positivamente o governo nos últimos quatro anos. Assim, para o ano de 2002, a variável indica se o eleitor avaliou positivamente o governo Fernando Henrique nos últimos quatro anos ou não (Ótimo, Bom ou Regular para bom = 1; Péssimo, Ruim ou Regular para ruim =0). Para os anos de 2006 e 2010, a avaliação refere-se ao governo Lula (Muito bom e Bom = 1; Ruim e Péssimo = 0). E em 2014 a avalição foi sobre o governo Dilma (Ótimo e Bom $=1 ;$ Regular, Ruim e Péssimo $=0$ ). Incluímos também variáveis que indicam se ele 
gosta de algum partido, uma indicando o PT e outra indicando o PSDB. De maneira semelhante, com exceção do ano de 2014, incluímos duas variáveis que indicam o partido no qual ele não votaria de jeito nenhum. E para as duas últimas eleições (2010 e 2014) incluímos uma variável que indica como o eleitor avalia a economia. Em 2010, a questão foi como o eleitor avalia a situação econômica do país (Ótima e Boa = 1; Regular, Ruim ou Péssima = 0). Em 2014, a questão foi se a atual situação econômica do Brasil está melhor, igual ou pior que há 12 meses (Melhor $=1$; Igual ou Pior $=0$ ). Para esses dois últimos anos também incluímos uma variável que indica se o entrevistado é beneficiário do programa Bolsa Família (2010) e/ou se alguém que vive em sua casa foi beneficiário do programa (2014).

É importante notar que precisamos ter cautela na intepretação dos resultados expostos na Tabela 3. A ideologia, além de estar associada ao voto, também está associada às variáveis de controle. Isto é, ela não é exógena ao processo eleitoral. Por exemplo, é razoável imaginar que ser de esquerda tem um impacto na probabilidade de se votar no candidato do PSDB, mas também tem um impacto na rejeição que o indivíduo tem a esse partido. Assim, ao mesmo tempo que a variável que indica essa rejeição é uma variável de controle (pois ela afeta a decisão eleitoral), ela também é uma variável dependente (pois ela é afetada pela ideologia). Esse tipo de variável é conhecido como de controle endógeno (Angrist e Pischke, 2008, p. 64-68). De modo intuitivo, o problema é que não é fácil assumir que a variável de controle (rejeição ao PSDB) se mantém constante quando modificamos a nossa variável explicativa (ideologia).

Vamos aos resultados. As variáveis que indicam gostar do PT ou do PSDB e que não votariam no PT ou no PSDB possuem os sinais esperados. Isto é, ter alguma afinidade com o PT tem uma associação negativa com o voto no candidato do PSDB. Por outro lado, ter uma afinidade com o PSDB está positivamente associado com o voto nesse partido. A avaliação do governo também possui a direção esperada para todos os anos. Avaliar positivamente o governo Fernando Henrique está positivamente associado ao voto no candidato José Serra em 2002. Já avaliar positivamente os governos petistas em 2002, 2006 e 2010 está negativamente associado ao voto no candidato do PSDB quatro anos mais tarde. A avaliação da economia, por sua vez, não se mostrou uma variável relevante no voto. Tanto para 2010 quanto para 2014 não encontramos resultados diferentes de zero. Por fim, a variável Bolsa Família só teve um impacto relevante na eleição de 2014. Em parte, isso pode ser explicado pelo modo como a pergunta foi formulada em 2010. Nesse ano, foi perguntado apenas se o entrevistado era beneficiário do programa, ao passo que em 2014 a questão foi mais ampla ao perguntar se alguém que vive na casa do entrevistado foi beneficiário.

Como podemos observar na Tabela 3, os coeficientes que indicam o impacto da posição ideológica (ponto ideal) sobre o voto se mantiveram positivos para todos os anos. Há uma redução do seu impacto, quando comparado aos resultados dos modelos bivariados com a inclusão de outros fatores que também influenciam a decisão dos eleitores. No entanto, a conclusão é a mesma que obtivemos com os modelos mais 
simples: quanto mais à esquerda da escala ideológica um eleitor está posicionado, maiores são as suas chances de votar no candidato de esquerda.

\section{Sofisticação política e voto}

Nesta seção verificamos se a probabilidade de um eleitor votar no candidato que está mais próximo dele varia conforme o seu nível de sofisticação política. Para isso podemos estender o modelo proposto na equação 15 incluindo um termo de interação:

$$
P\left(v_{i}=P S D B\right)=\Phi\left(Y_{0}+Y_{1} x_{i}+Y_{2} \text { sof }_{i}+Y_{3} x_{i} \text { sof }_{i}\right)
$$

onde sof $_{i}$ é o índice de sofisticação política do eleitor $i$. A conexão dos coeficientes do modelo de regressão com os parâmetros do modelo espacial é dada por:

$$
\begin{aligned}
& \delta_{i}=Y_{0}+\gamma_{2} \text { sof }_{i} \\
& a_{i}=\gamma_{1}+\gamma_{3} \text { sof }_{i}
\end{aligned}
$$

Mas, antes de estimarmos esse modelo, precisamos de uma medida de sofisticação política dos eleitores $\left(\right.$ sof $\left._{i}\right)$. A ideia de sofisticação política compreende diversas dimensões. Ou seja, ela não remete apenas a questões de conhecimento político, mas também inclui aspectos relacionados ao interesse por política, bem como a capacidade de organizar ideias políticas em termos abstratos. No entanto, como essas dimensões são correlacionadas entre si, é possível ter uma boa aproximação desse constructo utilizando um número reduzido de questões associadas a essas dimensões (Fuks e Pereira, 2011).

Neste artigo, utilizamos modelos da teoria da resposta ao item (IRT) aplicados a questões (itens) sobre importantes figuras do cenário político brasileiro e sobre o funcionamento do sistema político. Essa é a estratégia que tem sido utilizada pela literatura (Lawrence, 2007; Levendusky e Jackman, 2003; Pereira, 2013). Além disso, incluímos também diversos itens que remetem ao interesse por política e à participação política dos eleitores. Mesmo que imperfeita, essa medida nos fornece uma boa representação da diferença existente entre os indivíduos no que se refere à sofisticação política.

Para o ano de 2010, são utilizadas 21 questões de conhecimento político. Destas, quatro são questões fechadas do tipo "Certo" ou "Errado". Foi perguntado ao entrevistado o seguinte: "Gostaria que o(a) sr(a). dissesse se as seguintes frases estão certas ou erradas". Por exemplo, uma das afirmações era: "O presidente da República tem um mandato de 4 anos". O entrevistado deveria responder se essa afirmação era correta ou não. As demais questões (17) eram abertas. Era dito ao entrevistado o seguinte: "Vou ler para o(a) sr(a). o nome de alguns políticos e gostaria que me dissesse a qual partido eles são filiados". Por exemplo, uma das perguntas era "A qual partido Eduardo Suplicy é filiado?" Caso ele tenha respondido "PT", a resposta foi codificada como "Certo". Caso o entrevistado tenha respondido outro partido, "Não sabe" ou "Não respondeu", as respostas foram codificadas como "Errado". Para os demais anos foram feitas apenas quatro questões 
de conhecimento político. Mas, a despeito dessas diferenças, os resultados são semelhantes para todas as eleições ${ }^{11}$.

Para o ano de 2002, utilizamos 18 questões de interesse e participação política. Em 2006 temos cinco itens, em 2010 temos 10 e em 2014 utilizamos 19. Foram incluídas questões como: "Se o voto não fosse obrigatório o(a) $\operatorname{sr}(a)$. votaria?"; "Durante a campanha eleitoral o(a) sr(a). tentou convencer alguém a votar em algum candidato ou partido? (Se sim) Com que frequência: muitas vezes, algumas ou poucas vezes?". Também incluímos itens perguntando se o entrevistado era filiado a sindicato, associação profissional ou partido político ${ }^{12}$.

A principal vantagem de utilizar modelos de IRT é o fato de eles levarem em consideração a dificuldade das questões e como elas discriminam os respondentes ${ }^{13}$. Por exemplo, não é difícil perceber que a questão "De qual partido Lula é filiado?" não deve ter o mesmo peso que a questão "De qual partido Jorge Bornhausen é filiado?". A primeira questão provavelmente receberá muito mais respostas corretas do que a segunda.

No modelo de IRT de dois parâmetros, a probabilidade de um entrevistado $i$ responder corretamente ao item $q$ é dada por:

$$
P\left(q_{i k}=1\right)=\Phi\left(\text { sof }_{i} \Psi_{q}-\theta_{q}\right)
$$

onde $\psi$ é o parâmetro de discriminação e $\theta$ é o parâmetro de dificuldade da questão. Um item é dito mais difícil quando a probabilidade de acerto é menor que a de outro item, dado o mesmo nível de sofisticação política. O parâmetro de discriminação indica quão bem um item é capaz de discriminar entre um indivíduo mais sofisticado e um menos sofisticado.

Na implementação bayesiana (Fox, 2010) assume-se que:

$$
\begin{aligned}
& \text { sof }_{\mathrm{i}} \sim \mathrm{N}(0,1) \\
& \Psi_{\mathrm{q}} \sim \mathrm{N}_{+}(0 ; 0,01) \\
& \theta_{\mathrm{q}} \sim \mathrm{N}(0 ; 0,01)
\end{aligned}
$$

Para identificarmos o modelo, fixamos os parâmetros de discriminação e de dificuldade do primeiro item em zero.

\footnotetext{
11 As questões utilizadas estão nos Anexos.

12 As questões utilizadas estão nos Anexos.

13 As opções mais simples seriam apenas somar o número de respostas corretas (dando o mesmo peso para todos os itens) ou atribuir pesos diferentes a cada uma das questões. Estas não parecem ser as formas ideais, dado o grau de subjetividade na definição dos pesos de cada item.
} 
Tabela 4

Estimativas dos parâmetros do modelo espacial estendido

\begin{tabular}{|l|c|c|c|c|}
\hline \multirow{3}{*}{ Intercepto } & $\mathbf{2 0 0 2}$ & $\mathbf{2 0 0 6}$ & $\mathbf{2 0 1 0}$ & $\mathbf{2 0 1 4}$ \\
\cline { 2 - 5 } & $-0,55$ & $-0,51$ & $-0,26$ & $-0,08$ \\
\hline \multirow{3}{*}{ Ponto ideal } & {$[-0,65 ;-0,45]$} & {$[-0,64 ;-0,37]$} & {$[-0,34 ;-0,17]$} & {$[-0,14 ;-0,00]$} \\
\cline { 2 - 5 } & 1,51 & 0,98 & 2,15 & 1,05 \\
\hline \multirow{2}{*}{ Sofisticação } & {$[1,17 ; 1,85]$} & {$[0,67 ; 1,32]$} & {$[1,83 ; 2,46]$} & {$[0,83 ; 1,28]$} \\
\cline { 2 - 5 } & {$[-0,27 ;-0,02]$} & {$[-0,23 ; 0,27]$} & {$[-0,02 ; 0,17]$} & {$[-0,03 ; 0,15]$} \\
\hline \multirow{3}{*}{ Interação } & 0,75 & 0,43 & 1,14 & 0,52 \\
\cline { 2 - 6 } & {$[0,37 ; 1,11]$} & {$[-0,13 ; 1,03]$} & {$[0,81 ; 1,45]$} & {$[0,25 ; 0,82]$} \\
\hline \multirow{N}{*}{$\mathrm{N}$} & 973 & 536 & 1077 & 1501 \\
\hline
\end{tabular}

Fonte: Elaborada pelo autor com base em dados dos Esebs.

Nota: As estimativas são a mediana da distribuição a posteriori. Intervalos de credibilidade de $95 \%$ estão entre colchetes.

$\mathrm{Na}$ Tabela 4, temos os resultados do modelo 20. Para o ano de 2010, para os eleitores com um nível de sofisticação médio ( sof $_{i}=0,006$ ), os parâmetros $\delta=-0,26+0,07(0,006)=-0,26$ e $a=2,15+1,14(0,006)=2,16$ são muito semelhantes aos parâmetros encontrados na Tabela $2(\delta=-0,26$ e $a=1,67)$. Isso corrobora os achados anteriores indicando a existência de um pequeno viés favorável à candidata do PT e uma probabilidade maior de um eleitor de esquerda (direita) votar no candidato de esquerda (direita). Assim como indicam um baixo poder explicativo da variável de sofisticação política.

Para termos uma ideia mais clara das implicações desse resultado, podemos olhar para os gráficos da Figura $5 \mathrm{com}$ as probabilidades preditas pelo modelo. Aí apresentamos a probabilidade de se votar no candidato do PSDB em função dos pontos ideais dos eleitores por nível de sofisticação. Dividimos os eleitores em três grupos: baixa sofisticação $(0,25$ percentil de sof), média sofisticação (mediana de sof) e alta sofisticação $(0,75$ percentil de sof). Se a sofisticação política for importante na decisão do voto, esperamos que a probabilidade de um eleitor pouco sofisticado votar no candidato mais próximo dele seja muito diferente da probabilidade de um eleitor altamente sofisticado. Em outras palavras, eleitores pouco informados utilizariam componentes não espaciais na hora de votar, ao passo que eleitores informados utilizariam o critério ideológico. 


\section{Figura 5 \\ Probabilidade do voto no candidato do PSDB em função dos pontos ideais dos entrevistados por nível de sofisticação política}

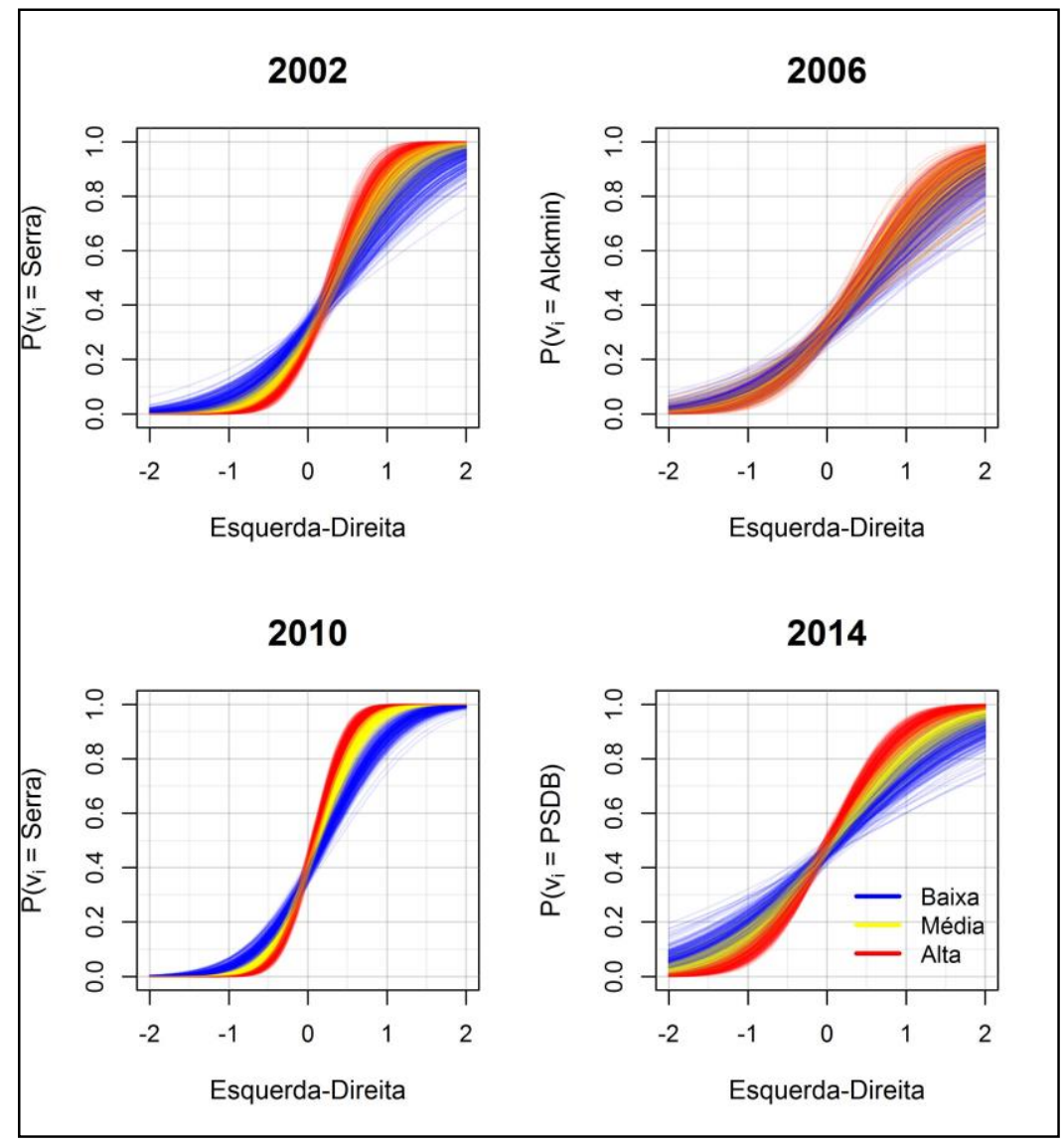

Fonte: Elaborada pelo autor com base em dados dos Esebs.

Nota: Cada gráfico possui 250 curvas calculadas a partir de 250 amostras da distribuição a posteriori dos coeficientes do modelo de regressão.

Os resultados da Figura 5 contradizem a ideia de que eleitores menos informados votariam de uma forma diferente da de eleitores mais sofisticados. Diferentes níveis de sofisticação política pouco afetam a probabilidade de um eleitor votar no candidato que está mais próximo dele.

Vejamos as eleições de 2010 no caso de um eleitor com ponto ideal igual a 0,5. Se esse eleitor for altamente sofisticado, a probabilidade de ele votar no candidato do PSDB é de $87,8 \%$. Se ele possuir um nível médio de sofisticação, essa probabilidade é de 79,5\%. E se ele for pouco sofisticado, a probabilidade é de 67,2\%. Embora essas probabilidades aumentem com o nível de informação política, não podemos afirmar que eleitores menos informados guiem os seus votos por critérios não espaciais. Isso fica mais claro para as outras eleições. Para as eleições de 2002, um eleitor muito sofisticado tem $63,3 \%$ de chances de votar no candidato Serra, enquanto eleitores com um nível de sofisticação 
médio e baixo tem $58,4 \%$ e $53,2 \%$ de chances, respectivamente. Como é possível atestar pela Figura 5, a diferença entre os grupos é praticamente inexistente durante as eleições de 2006. Ser muito ou pouco sofisticado não altera as chances de escolher o candidato mais próximo do ponto de vista ideológico. Em 2014, o cenário é semelhante. Um eleitor pouco sofisticado tem $60,8 \%$ de chances de votar no candidato do PSDB, já eleitores com um nível médio e alto de sofisticação possuem probabilidade de 65,5\% e 73,4\%, respectivamente.

Para eleitores indiferentes $\left(x_{i}=0\right)$, as conclusões são semelhantes. Para as eleições de 2010, se o eleitor for muito sofisticado, a probabilidade de ele votar no candidato do PSDB é de $41,3 \%$. Se ele possuir um nível médio, a probabilidade é de $39,8 \%$. E se ele for pouco sofisticado, a probabilidade é de $38,2 \%$. Ou seja, para todos os níveis de sofisticação, a candidata do PT possuía uma vantagem baseada em um componente não espacial. Essa vantagem era maior quanto menor a sofisticação do eleitor. Mas, novamente, não podemos afirmar que eleitores menos informados votariam por critérios não espaciais e eleitores sofisticados votariam por critérios ideológicos, ambos os tipos de eleitores levam em consideração a distância relativa dos candidatos e isso vale para os outros pleitos. Em 2002, eleitores com um nível de sofisticação baixo, médio e alto tinham $32,3 \%, 29,2 \%$ e $26,3 \%$ de chances de votar no candidato do PSDB, respectivamente. Em 2006, as probabilidades foram de 30,4\% (baixo), 30,6\% (médio) e 30,7\% (alto). Por fim, em 2014 o cenário foi muito semelhante, 45,6\% (baixo), 46,6\% (médio) e 48,4\% (alto). 
Tabela 5

Estimativas dos parâmetros do modelo espacial estendido com controles

\begin{tabular}{|c|c|c|c|c|}
\hline & 2002 & 2006 & 2010 & 2014 \\
\hline \multirow{2}{*}{ Intercepto } & $-1,04$ & 0,56 & 0,16 & 0,68 \\
\hline & {$[-1,28 ;-0,78]$} & {$[0,12 ; 0,99]$} & {$[-0,46 ; 0,84]$} & {$[0,55 ; 0,80]$} \\
\hline \multirow{2}{*}{ Ponto ideal } & 0,60 & 0,50 & 1,21 & 0,71 \\
\hline & {$[0,20 ; 1,03]$} & {$[0,02 ; 0,97]$} & {$[0,81 ; 1,64]$} & {$[0,44 ; 0,96]$} \\
\hline \multirow{2}{*}{ Sofisticação } & $-0,10$ & 0,00 & $-0,05$ & 0,05 \\
\hline & {$[-0,24 ; 0,04]$} & {$[-0,41 ; 0,36]$} & {$[-0,18 ; 0,09]$} & {$[-0,06 ; 0,17]$} \\
\hline \multirow{2}{*}{ Interação } & 0,46 & $-0,29$ & 0,75 & 0,33 \\
\hline & {$[0,02 ; 0,88]$} & {$[-1,25 ; 0,57]$} & {$[0,35 ; 1,14]$} & {$[-0,02 ; 0,64]$} \\
\hline \multirow{2}{*}{ Avaliação do governo } & 0,56 & $-1,47$ & $-0,24$ & $-1,22$ \\
\hline & {$[0,23 ; 0,80]$} & {$[-1,95 ;-0,99]$} & {$[-0,91 ; 0,37]$} & {$[-1,39 ;-1,04]$} \\
\hline \multirow{2}{*}{ Gosta do PT } & $-0,52$ & $-0,99$ & $-0,98$ & $-1,50$ \\
\hline & {$[-0,83 ;-0,24]$} & {$[-1,75 ;-0,41]$} & {$[-1,25 ;-0,70]$} & {$[-1,87 ;-1,20]$} \\
\hline \multirow{2}{*}{ Gosta do PSDB } & 0,54 & 0,39 & 0,94 & 1,08 \\
\hline & {$[0,10 ; 0,97]$} & {$[-0,22 ; 1,05]$} & {$[0,59 ; 1,29]$} & {$[0,75 ; 1,47]$} \\
\hline \multirow{2}{*}{ Não votaria no PT } & 1,64 & 1,51 & 1,52 & - \\
\hline & {$[1,33 ; 1,93]$} & {$[1,08 ; 1,93]$} & {$[1,16,192]$} & \\
\hline \multirow{2}{*}{ Não votaria no PSDB } & $-0,38$ & $-0,94$ & $-1,12$ & - \\
\hline & {$[-0,66 ;-0,11]$} & {$[-1,43 ;-0,50]$} & {$[-1,39 ;-0,84]$} & \\
\hline \multirow{2}{*}{ Avaliação da economia } & - & - & $-0,04$ & $-0,08$ \\
\hline & & & {$[-0,27 ; 0,20]$} & {$[-0,28 ; 0,12]$} \\
\hline \multirow{2}{*}{ Bolsa Família } & - & - & $-0,13$ & $-0,40$ \\
\hline & & & {$[-0,46 ; 0,18]$} & {$[-0,61 ;-0,20]$} \\
\hline $\mathrm{N}$ & 915 & 469 & 990 & 1450 \\
\hline
\end{tabular}

Fonte: Elaborada pelo autor com base em dados dos Esebs.

Nota: As estimativas são a mediana da distribuição a posteriori. Intervalos de credibilidade de $95 \%$ estão entre colchetes.

A inclusão de variáveis de controle não altera as nossas conclusões. Na Tabela 5 apresentamos os resultados do modelo 20, incluindo as mesmas variáveis de controle utilizadas na seção anterior. Como é possível observar, os coeficientes que indicam o impacto da ideologia sobre o comportamento eleitoral continuam positivos para todas as eleições. Quando comparado aos resultados da Tabela 4, há uma redução da magnitude dos coeficientes, mas ainda são resultados substancialmente relevantes. De maneira semelhante, o coeficiente para a sofisticação política e para a interação entre a sofisticação e a ideologia também teve a sua magnitude reduzida, mas sem mudanças substantivas. 


\section{Conclusões}

O objetivo deste artigo foi testar empiricamente o principal pressuposto da teoria espacial do voto no Brasil. De acordo com esse modelo, eleitores devem votar no candidato que está mais próximo deles do ponto de vista ideológico. Se eles forem indiferentes às opções oferecidas, a probabilidade de eles escolherem qualquer um dos candidatos deve ser igual. Além disso, os resultados devem ser independentes do nível de sofisticação dos eleitores. Isto é, o fato de um eleitor ser pouco informado não deve alterar significativamente essas probabilidades.

Como vimos, o modelo espacial parece prever razoavelmente bem o comportamento dos eleitores brasileiros. E isso vale para todos os níveis de sofisticação política. Eleitores altamente sofisticados se encaixam quase perfeitamente no modelo espacial. Eles possuem uma alta probabilidade de votar no candidato que está mais próximo deles. Se eles estiverem no ponto de indiferença, a probabilidade de eles escolherem qualquer um dos dois candidatos é de quase $50 \%$. A literatura brasileira sobre comportamento eleitoral (Carreirão, 2002) não tinha muitas dúvidas sobre esse resultado. A parcela mais informada da população guiaria o seu voto a partir de elementos ideológicos.

A dúvida estaria sobre a parcela menos informada da população. Esse subconjunto de eleitores, que seria a parcela predominante do eleitorado brasileiro, utilizaria elementos não ideológicos na hora do voto. Os resultados apresentados neste artigo mostram um cenário diferente. A probabilidade de esses eleitores escolherem um candidato que está mais próximo deles é extremamente alta.

Isso contraria parte da literatura que afirma que a ideologia não é relevante - ou o é apenas para a parcela mais educada da população (Carreirão, 2002, 2007; Holzhacker e Balbachevsky, 2007; Nicolau, 2014). Diversos trabalhos argumentam que somente os eleitores altamente informados votariam de forma ideológica, no sentido de escolher os partidos e candidatos que mais se aproximam de suas próprias posições políticas. A grande maioria do eleitorado basearia os seus votos em elementos não espaciais, como a avaliação do desempenho do governo e atributos pessoais dos candidatos. Por outro lado, os nossos resultados vão ao encontro dos achados da literatura que sustenta a importância preditiva da autolocalização na escala esquerda-direita sobre o voto (Singer, 1999; Amaral e Ribeiro, 2015). Como os eleitores são pouco informados e não conseguem relacionar cada decisão tomada pelo governo com as suas próprias posições políticas, a ideologia seria relevante na medida em que ela criaria um atalho que eliminaria a necessidade de se manter informado. Assim, este artigo buscou contribuir com a literatura de comportamento político e, em especial, com a discussão sobre o papel da ideologia no comportamento eleitoral, argumentando favoravelmente sobre a utilidade da variável ideologia no entendimento das eleições presidenciais no Brasil.

Mas é importante notar que a noção de ideologia com a qual estamos dialogando não é aquela associada a um sistema de crenças estruturado, em que um eleitor ideológico 
IDEOLOGIA, SOFISTICAÇÃO POLÍTICA E VOTO NO BRASIL

seria aquele que possui um conjunto de opiniões políticas que são interconectadas e estáveis ao longo do tempo. Como estamos testando o principal pressuposto da teoria espacial do voto, temos uma visão menos exigente daquilo que seria um voto ideológico. Sob essa perspectiva, um eleitor ideológico seria aquele que escolhe o candidato que possui a posição política mais próxima da sua, sem levar em consideração outros elementos. Além disso, o nível de sofisticação política do eleitor pouco influenciaria nesse processo. Os resultados apresentados neste artigo parecem ir nessa direção e o cenário político atual dá indícios de que a ideologia permanecerá como uma variável importante no comportamento eleitoral. Com o aprofundamento da polarização ideológica tanto no nível das elites políticas quanto no do eleitorado, esquerda e direita continuarão tendo um papel relevante.

Do ponto de vista metodológico, procuramos mostrar que a principal estratégia adotada pela literatura para mensurar a ideologia dos eleitores é problemática. A utilização dos dados brutos da autolocalização na escala esquerda-direita possui problemas de incomparabilidade interpessoal, uma vez que os entrevistados podem interpretar a escala ideológica de formas muito diferentes. Para avançar nessa questão, utilizamos a solução proposta por Aldrich e McKelvey (1977) e implementada em uma versão bayesiana por Hare et al. (2014). Com isso, buscamos contribuir com a literatura trazendo melhores medidas de identificação ideológica que podem ter impactos substantivos na forma como vemos a relação entre ideologia e voto.

\section{Referências bibliográficas}

ALDRICH, J.; MCkELVEY, R. "A method of scaling with applications to the 1968 and 1972 presidential elections". The American Political Science Review, vol. 71, no 1, p. 111-130, 1977.

AlmeidA, A. "À esquerda dos números, à direita dos fatos". Insight Inteligência, vol. 15, p. 113-128, 2001.

AMARAL, O.; RIBEIRO, P. "Por que Dilma de novo? Uma análise exploratória do Estudo Eleitoral Brasileiro de 2014". Revista de Sociologia e Política, vol. 23, no 56, p. 107-123, 2015.

AMES, B.; SMITH, E. "Knowing left from right: ideological identification in Brazil, 2002-2006". Journal of Politics in Latin America, vol. 2, no 3, p. 3-38, 2010.

ANGRIST, J.; PISCHKE, J. Mostly harmless econometrics: an empiricist's companion. New Jersey: Princeton University Press, 2008.

BRADY, H. "The perils of survey research: inter-personally incomparable responses". Political Methodology, vol. 11, no 3-4, p. 269-291, 1985.

CAmpBell, A., et al. The American voter. Chicago: University of Chicago Press, 1980.

CARREIRÃo, Y. A decisão do voto nas eleições presidenciais brasileiras. Rio de Janeiro: Editora FGV, 2002. "Identificação ideológica, partidos e voto na eleição presidencial de 2006". Opinião Pública, vol. 13, no 2, p. 307-339, 2007.

CASTRO, M. "Determinantes do comportamento eleitoral - a centralidade da sofisticação política". Tese de doutorado. Rio de Janeiro: Iuperj, 1994.

CESOP. Estudo Eleitoral Brasileiro (Eseb) 2002, Cesop-FGV/Brasil - 2 dez. - no 01838; Eseb 2006 - 
Cesop-Ipsos/Brasil - 6 dez. - no 02489; Eseb 2010 - Cesop-Vox Populi/Brasil - 10 nov. - no 02639; Eseb 2014 - Cesop-Ibope/Brasil - nov. - no 03928. In: Banco de Dados do Centro de Estudos de Opinião Pública (CESOP), Unicamp, Campinas, 2002, 2006, 2010, 2014.

CLINTON, J.; JACKMAN, S.; RIVERS, D. "The statistical analysis of roll call data". American Political Science Review, vol. 98, n² 2, p. 355-370, 2004.

CONVERSE, P. The nature of belief systems in mass publics. In: APTER, D. (ed.). Ideology and discontent. New York: Free Press, 1964.

DAHL, R. Poliarquia: participação e oposição. São Paulo: Edusp, 1997.

Downs, A. An economic theory of democracy. Nova York: Harper and Row, 1957.

ENELOW, J.; HINICH, M. "Nonspatial candidate characteristics and electoral competition". The Journal of Politics, vol. 44, n 1, p. 115-130, 1982.

Enelow, J.; Hinich, M. The spatial theory of voting: an introduction. Cambridge: Cambridge University Press, 1984.

Fox, J. Bayesian item response modeling: theory and applications. Nova York: Springer Science \& Business Media, 2010.

FUKS, M.; PEREIRA, F. "Informação e conceituação: a dimensão cognitiva da desigualdade política entre jovens de Belo Horizonte". Revista Brasileira de Ciências Sociais, vol. 26, no 76, p. 123-143, 2011.

HARE, C., et al. "Using bayesian Aldrich-McKelvey scaling to study citizens' ideological preferences and perceptions". American Journal of Political Science, vol. 59, no 3, p. 759-774, 2014.

HINICH, M.; MUNGER, M. Ideology and the theory of political choice. Michigan: The Michigan University Press, 1994.

HOLZHACKER, D.; BALBACHEVSKY, E. "Classe ideologia e política: uma interpretação dos resultados das eleições de 2002 e 2006". Opinião Pública, vol. 13, n 2, p. 283-306, 2007.

JESSEE, S. Ideology and spatial voting in American elections. Cambridge: Cambridge University Press, 2012.

KING, G., et al. "Enhancing the validity and cross-cultural comparability of measurement in survey research". American Political Science Review, vol. 98, no 1, p. 191-207, 2004.

LAMOUNIER, B. Presidente Prudente: o crescimento da oposição num reduto arenista. In: REIS, F. (org.). Os partidos e o regime. São Paulo: Símbolo, 1978.

LAWRENCE, C. "Should voters be encyclopedias? Measuring political sophistication of survey respondents". In: Midwest Political Science Association Meeting, Chicago, 2007.

LEVENDUSKY, M.; JACKMAN, S. "Reconsidering the measurement of political knowledge". Unpublished manuscript, Stanford University, 2003.

LO, J.; PROKSCH, S.; GSCHWEND, T. "A common left-right scale for voters and parties in Europe". Political Analysis, vol. 22, no 2, p. 205-223, 2014.

Nicolau, J. "Determinantes do voto no primeiro turno das eleições presidenciais brasileiras de 2010 : uma análise exploratória". Opinião Pública, vol 20, n 3, p. 311-325, 2014.

Oliveira, C.; TURGEON, M. "Ideologia e comportamento político no eleitorado brasileiro". Opinião Pública, vol. 21, no 3, p. 574-600, 2015.

Pereira, F. "Sofisticação política e opinião pública no Brasil: revisitando hipóteses clássicas". Opinião Pública, vol. 19, n² 2, p. 291-319, 2013.

POWER, T.; ZUCCO, C. "Estimating ideology of Brazilian legislative parties, 1990-2005: a research communication". Latin American Research Review, vol. 44, n 1, p. 218-246, 2009.

REIS, F. Classe social e opção partidária: as eleições de 1976 em Juiz de Fora. In: REIS, F. (org.). Os partidos e o regime. São Paulo: Símbolo, 1978. 
IDEOLOGIA, SOFISTICAÇÃO POLÍTICA E VOTO NO BRASIL

REIS, F. Mercado e utopia: teoria política, sociedade brasileira. São Paulo: Edusp, 2000.

REIS, F.; CASTRO, M. "Democracia, civismo e cinismo: um estudo empírico sobre normas e racionalidade". Revista Brasileira de Ciências Sociais, vol. 16, no 45, p. 25-46, 2006.

SAIEGH, S. "Using joint scaling methods to study ideology and representation: evidence from Latin America". Political Analysis, vol. 23, no 3, p. 363-384, 2015.

SINGER, A. Esquerda e direita no eleitorado brasileiro: a identificação ideológica nas disputas presidenciais de 1989 e 1994. São Paulo: Edusp, 1999.

SOARES, G. "Em busca da racionalidade perdida: alguns determinantes do voto no Distrito Federal". Revista Brasileira de Ciências Sociais, vol. 15, no 43, p. 5-23, 2000. 


\section{Anexos}

Figura 6

Estímulos e distribuição dos entrevistados

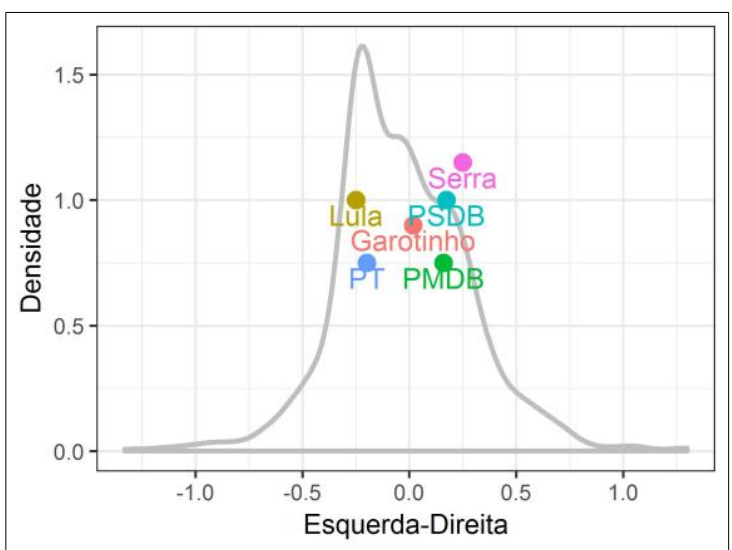

Fonte: Elaborada pelo autor com base em dados do Eseb 2002.

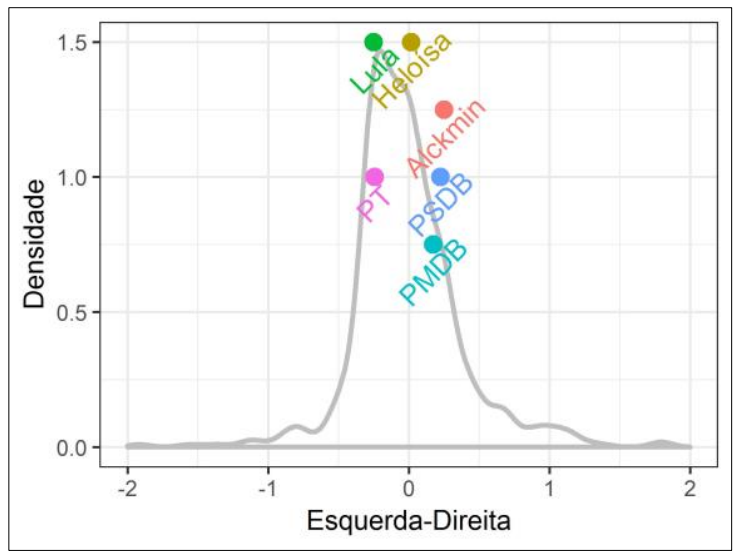

Fonte: Elaborada pelo autor com base em dados do Eseb 2006.

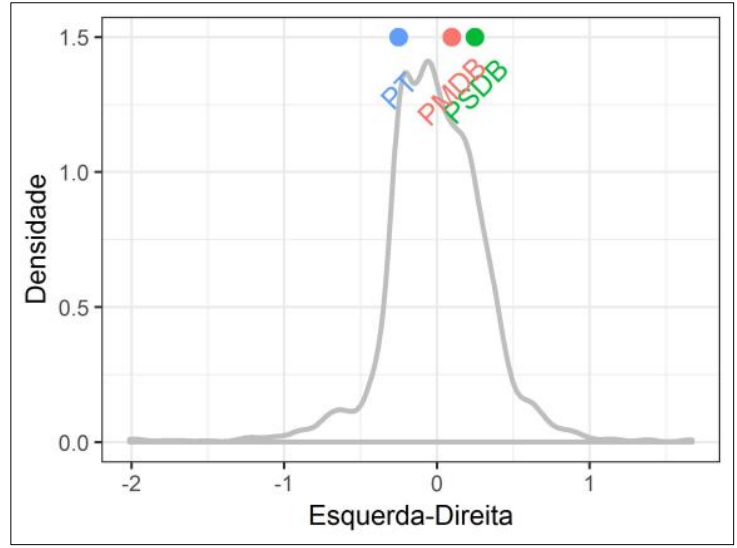

Fonte: Elaborada pelo autor com base em dados do Eseb 2014. 
Figura 7

Comparação entre o autoposicionamento e os pontos ideais estimados

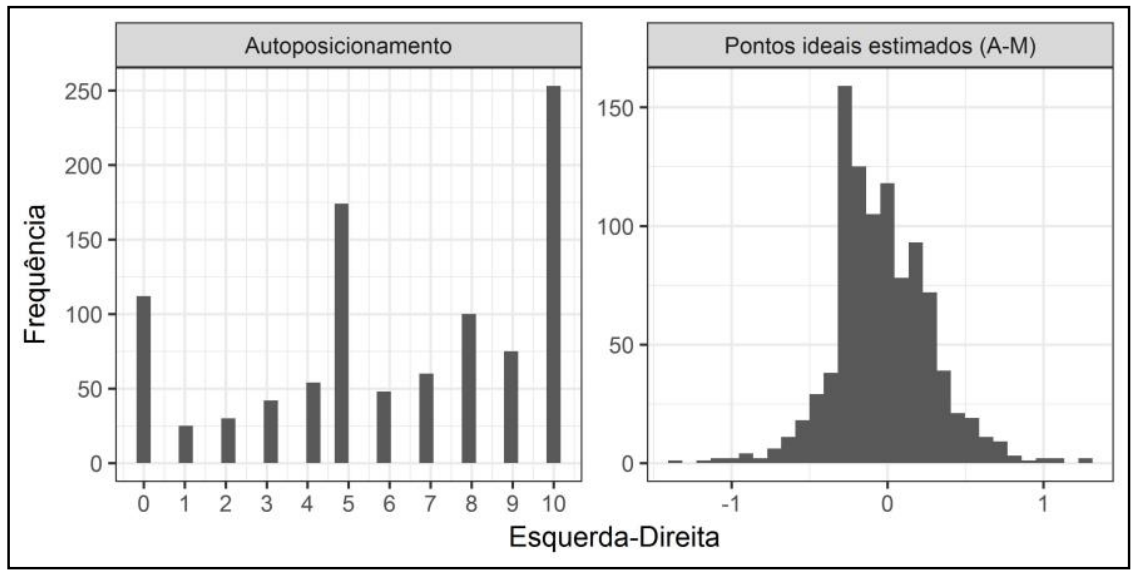

Fonte: Elaborada pelo autor com base em dados do Eseb 2002.

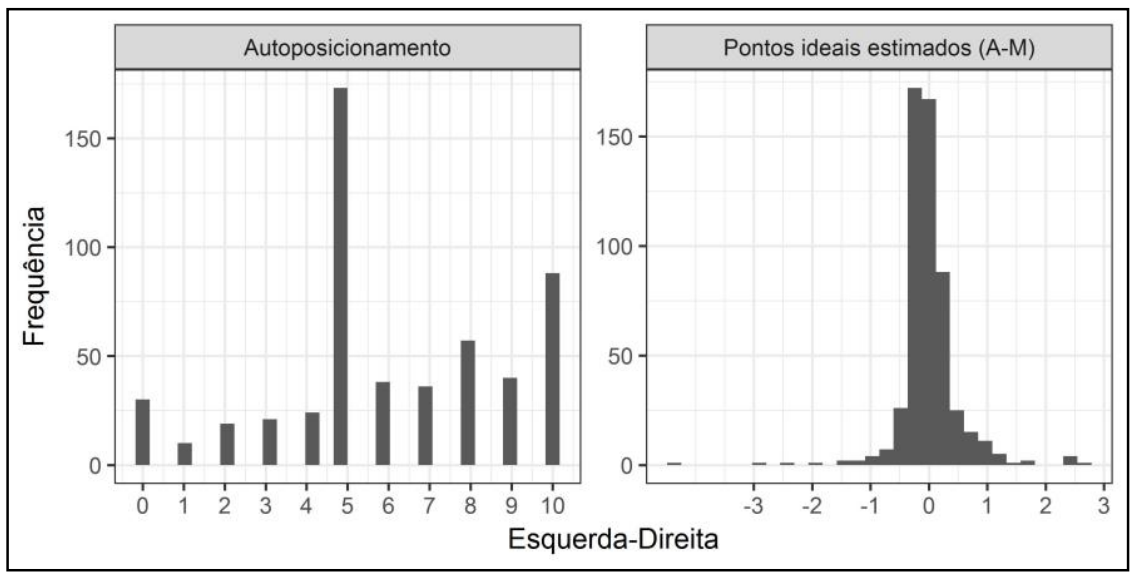

Fonte: Elaborada pelo autor com base em dados do Eseb 2006.

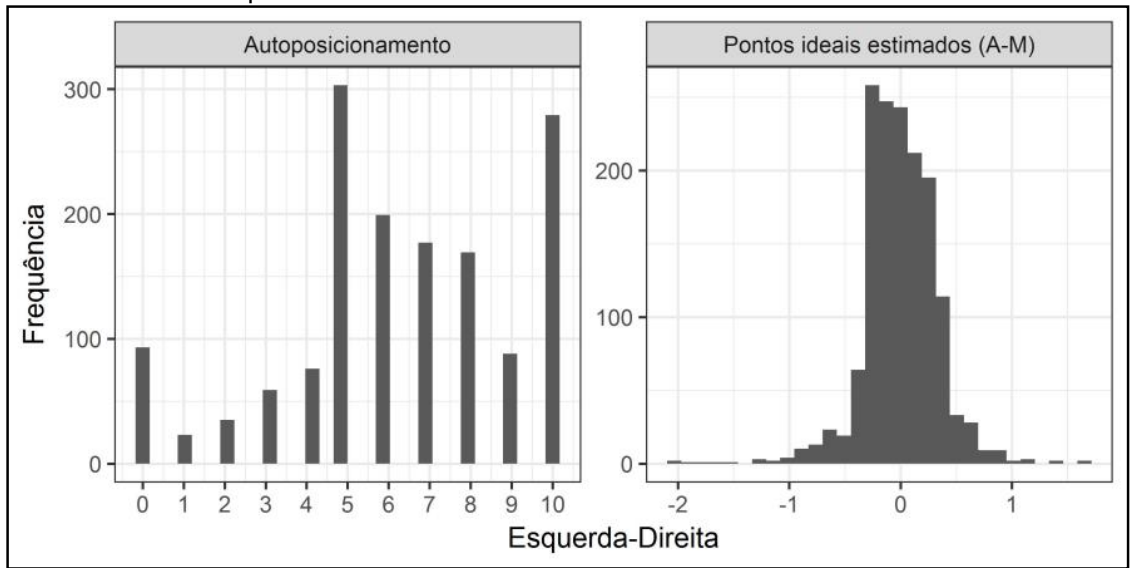

Fonte: Elaborada pelo autor com base em dados do Eseb 2014. 
Figura 8

Distribuição dos entrevistados por voto

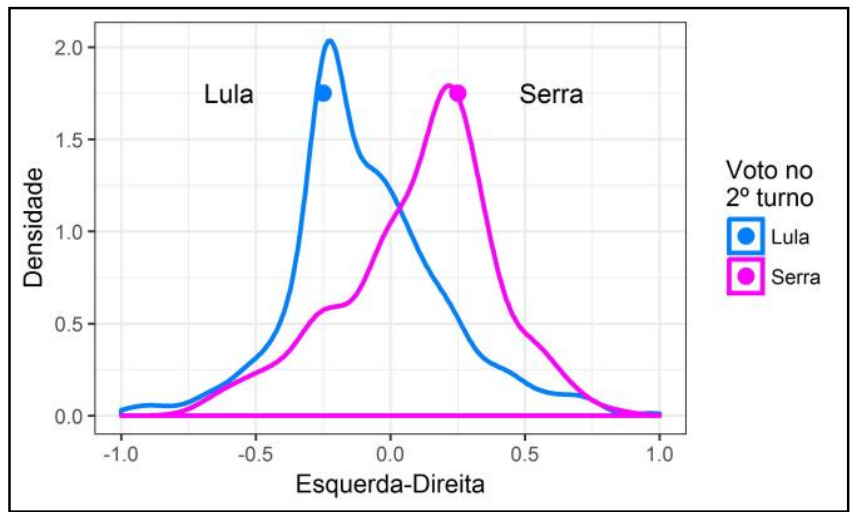

Fonte: Elaborada pelo autor com base em dados do Eseb 2002.

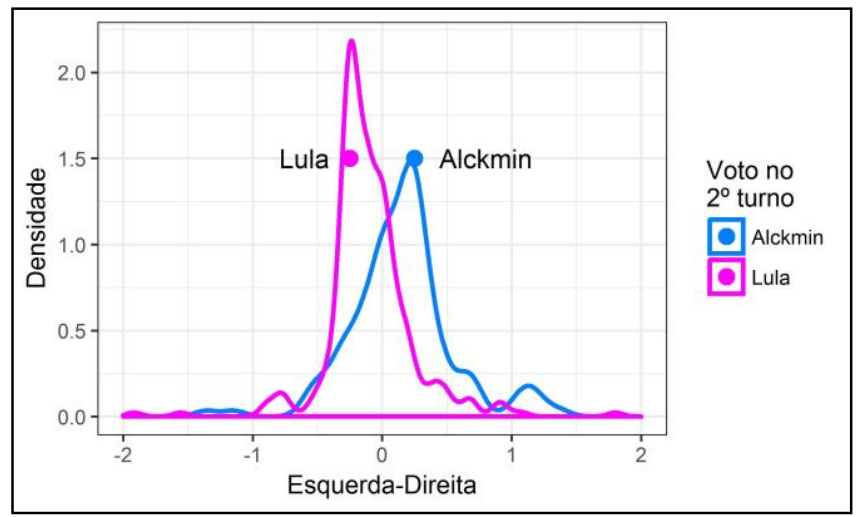

Fonte: Elaborada pelo autor com base em dados do Eseb 2006.

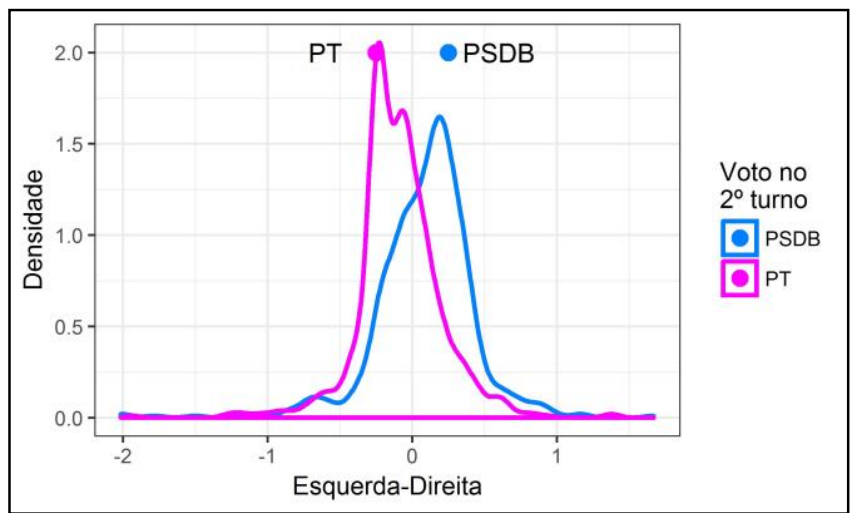

Fonte: Elaborada pelo autor com base em dados do Eseb 2014. 


\section{Questões de sofisticação política - Esebs}

\section{2}

1. Na sua opinião, qual é o partido do presidente Fernando Henrique Cardoso?

2. Na sua opinião, o número 13 é de qual partido?

3. Nessa eleição, Denise Frossard foi eleita deputada estadual, deputada federal ou senadora?

4. E Carlos Minc, foi eleito Deputado Estadual, Deputado Federal ou Senador?

5. Durante a campanha eleitoral o(a) sr(a). tentou convencer alguém a votar em algum candidato ou partido? (Se sim) Com que freqüência: muitas, algumas ou poucas vezes?

6. Durante as eleições o(a) sr(a). mostrou seu apoio a algum candidato ou partido participando de reuniões, colando cartazes ou distribuindo panfletos? (Se sim) Com que freqüência: muitas, algumas ou poucas vezes?

7. E o(a) sr(a). colocou faixas ou cartazes de algum candidato em sua casa, no trabalho, ou colou adesivo no carro?

8. Nos últimos 4 anos o(a) sr(a). fez contato com algum político, ou alguém que trabalha no governo, para pedir a solução de algum problema que prejudicava muitas pessoas ou reclamar do próprio governo?

9. Nos últimos 4 anos, o(a) sr(a). participou de algum protesto ou comício contra ou a favor do governo?

10. Se o voto não fosse obrigatório, o(a) sr(a). votaria?

11. $\mathrm{O}(\mathrm{A}) \operatorname{sr}(\mathrm{a})$. costuma ler jornal?

12. $\mathrm{O}(\mathrm{A}) \operatorname{sr}(\mathrm{a})$. assistiu a telejornais com notícias nacionais essa semana?

13. E telejornais de notícias locais, o(a) sr(a). assistiu essa semana?

14. $\mathrm{O}(\mathrm{A}) \operatorname{sr}(\mathrm{a})$. ouviu notícias no rádio esta semana?

15. Com que frequência o(a) sr(a). conversa sobre política com parentes e amigos, todo dia, às vezes, raramente ou nunca?

16. Agora eu gostaria de saber quais destas atividades o(a) $\operatorname{sr}(a)$. já fez em algum momento da sua vida e quais o(a) sr(a). nunca fez:

a) Assinar um abaixo assinado

b) Participar de manifestações ou protestos

c) Participar de greve

19. $O(A) \operatorname{sr}(a)$. é filiado(a) a algum .........?

a) Sindicato

b) Associação profissional

c) Partido político

22. $\mathrm{O}(\mathrm{A}) \operatorname{sr}(\mathrm{a})$. costuma se informar sobre o trabalho de algum político?

\section{6}

Agora, para finalizar, gostaria que o(a) sr(a) dissesse se as seguintes frases estão certas ou erradas:

1. Geraldo Alckmin pertence ao PTB.

2. O presidente da República tem um mandato de 4 anos.

3. Os deputados da Câmara Federal são eleitos pelo voto majoritário.

4. O presidente Lula foi eleito pelo PT.

5. Se o voto não fosse obrigatório o(a) sr(a). votaria?

6. $O(A) \operatorname{sr}(a)$. ou alguém da sua casa é filiado(a) a algum ..?

a) Sindicato

b) Associação profissional

c) Associação de empresários ou comerciantes

d) Movimento social

\section{0}

1. Geraldo Alckmin é filiado ao PTB?

2. O presidente da República tem um mandato de 4 anos?

3. Os deputados da Câmara Federal são eleitos pelo voto majoritário?

4. O presidente Lula quando foi eleito era filiado ao PT? 
5. A qual partido Aécio Neves é filiado?

6. A qual partido Aloísio Mercadante é filiado?

7. A qual partido Ciro Gomes é filiado?

8. A qual partido Eduardo Suplicy é filiado?

9. A qual partido Fernando Henrique Cardoso é filiado?

10. A qual partido Itamar Franco é filiado?

11. A qual partido Jorge Bornhausen é filiado?

12. A qual partido José Aníbal é filiado?

13. A qual partido José Dirceu é filiado?

14. A qual partido José Sarney é filiado?

15. A qual partido José Serra é filiado?

16. A qual partido Lula é filiado?

17. A qual partido Marco Maciel é filiado?

18. A qual partido Marina Silva é filiada?

19. A qual partido Michel Temer é filiado?

20. A qual partido Pedro Simon é filiado?

21. A qual partido Roseana Sarney é filiada?

22. Como o(a) sr(a). acompanhou a campanha eleitoral?

23. Se o voto não fosse obrigatório o(a) $\operatorname{sr}(a)$. votaria?

24. $O(A) \operatorname{sr}(a)$. ou alguém da sua casa é filiado(a) a algum:

a) Sindicato

b) Associação profissional

c) Associação de empresários ou comerciantes

d) Movimento social

28. $O(A) \operatorname{sr}(a)$. costuma ler jornal?

29. $O(A) \operatorname{sr}(a)$. assistiu a telejornais com notícias nacionais essa semana?

30. E aos debates na TV entre candidatos a presidente, o(a) $\operatorname{sr}(a)$. assistiu?

31. $\mathrm{O}(\mathrm{A}) \mathrm{sr}(\mathrm{a})$. conhece ou já ouviu falar sobre os programas sociais e de redistribuição de renda do governo federal?

\section{4}

1. Pelo que o(a) sr(a). sabe ou ouviu falar, qual dessas pessoas foi o ministro da Fazenda durante o governo Dilma?

2. E pelo que o(a) sr(a). sabe ou ouviu falar, qual dessas foi a taxa de desemprego do Brasil em agosto de 2014?

3. E pensando no que o(a) sr(a). sabe ou ouviu falar, qual é hoje o segundo maior partido na Câmara dos Deputados?

4. Qual dessas pessoas é o atual secretário-geral da ONU - Organização das Nações Unidas?

5. Antes ou durante a campanha eleitoral deste ano o(a) $\operatorname{sr}(a)$. usou a internet ou o celular para acessar informações ou comunicados de algum partido ou candidato?

6. Agora eu gostaria de saber se:

a) $O(a)$ sr(a). é filiado a algum sindicato?

b) Alguém mais da sua casa é filiado a algum sindicato?

c) $\mathrm{O}(\mathrm{a}) \mathrm{sr}(\mathrm{a})$. é membro de alguma associação de comerciantes ou empresários?

d) $\mathrm{O}(\mathrm{a}) \mathrm{sr}(\mathrm{a})$. é membro de alguma associação de fazendeiros/sitiantes/produtores rurais?

e) $\mathrm{O}(\mathrm{a}) \mathrm{sr}(\mathrm{a})$. é membro de alguma associação profissional?

f) $\mathrm{O}(\mathrm{a}) \mathrm{sr}(\mathrm{a})$. é filiado a algum partido político?

12. Nas eleições deste ano, se o voto não fosse obrigatório o(a) sr(a). teria ido votar?

13. Agora vou citar algumas atividades e gostaria de saber se o(a) sr(a). já fez esta atividade em algum momento da sua vida.

a) Assinar um abaixo-assinado (inclusive na internet)

b) Participar de manifestações ou protestos de rua

c) Participar de greve

d) Participar de bloqueio de estradas

e) Participar de ocupação de prédios públicos

f) Participar de ocupação de terras

g) Utilizar a internet ou redes sociais para manifestações e debates políticos

20. O(a) sr(a). costuma ler jornal? 
IDEOLOGIA, SOFISTICAÇÃO POLÍTICA E VOTO NO BRASIL

21. Essa semana o(a) sr(a). assistiu a algum telejornal de transmissão nacional, ou seja, que passa em todo o Brasil?

22. E essa semana o(a) sr(a). assistiu a algum telejornal regional, ou seja, que passa notícias de sua cidade ou região?

23. $\mathrm{O}(\mathrm{a}) \operatorname{sr}(\mathrm{a})$. ouviu notícias no rádio esta semana?

Abstract
Ideology, political sophistication and vote in Brazil

The spatial theory of voting assumes that voters will cast their votes for the candidate whose policy position is closest to their own views. The goal of this paper is twofold: the first one is to test this assumption for the Brazilian presidential elections from 2002 to 2014. In order to do that we use data from the Brazilian Electoral Study along with scaling methods. The results suggest that the probability of a voter casting her vote for the candidate whose policy position is closest to her own is pretty high. The second goal of this paper is to assess if this result holds despite voters' political sophistication. In other words, we test if ill-informed voters make their electoral decisions based on non-spatial candidate characteristics. The results contradict this idea. Politically ill-informed voters also choose the candidates whose views are closer to their own.

Keywords: elections; ideology; political sophistication; spatial theory of voting

\section{Resumen}

Ideología, sofisticación política y voto en Brasil

La teoría espacial del voto parte del supuesto de que electores frente a dos (o más) candidatos elegirán aquel que esté más próximo de sus preferencias políticas. El primer objetivo del presente estudio será testar ese supuesto para las elecciones presidenciales en Brasil entre 2002 y 2014 . Para este fin, utilizamos los datos del Estudio Electoral Brasileño y técnicas de escalonamiento Los resultados muestran que la probabilidad que un elector vote en un candidato que esté más cercano de su punto de vista ideológico es considerablemente alta. El segundo objetivo de este estudio es averiguar si ese mismo resultado se sostiene independientemente del nivel de sofisticación política del elector, o sea, testamos la hipótesis de que electores poco informados tomarían sus decisiones basándose en elementos no espaciales (no ideológicos). Los resultados no respaldan esa idea; electores poco sofisticados políticamente también eligen los candidatos más similares a ellos mismos ideológicamente.

Palabras-clave: elecciones; ideología; sofisticación política; teoría espacial del voto

\section{Résumé}

Idéologie, sophistication politique et vote au Brésil

La théorie spatiale du vote présuppose que les électeurs qui sont face à deux candidats (ou plus) vont choisir celui qui est plus proches de leurs préférences. Le premier objectif de ce travail sera de tester cette hypothèse pour les élections présidentielles au Brésil entre 2002 et 2014. Pour cela, on utilise les données de l'Étude Electorale Brésilienne et des techniques d'échelonnement. Les résultats montrent que la probabilité qu'un électeur vote pour le candidat le plus proche de son point de vue idéologique est très élevée. Le second objectif de ce travail est de vérifier si le résultat se maintient malgré le niveau de sophistication politique de l'électeur. C'est-à-dire qu'on teste I'hypothèse selon laquelle les électeurs peu informés prendraient leurs décisions à partir d'éléments non spatiaux (non idéologiques). Les résultats contrarient cette idée. Des électeurs peu sophistiqués du point de vue politique choisissent aussi des candidats qui sont proches d'eux. Mots-clés: élections; idéologie; sophistication politique; théorie spatiale du vote

Artigo submetido à publicação em 20 de março de 2018. Versão final aprovada em 19 de março de 2019.

Opinião Pública adota a licença Creative Commons CC-BY. 